\title{
Mood disorders and complementary and alternative medicine: a literature review
}

This article was published in the following Dove Press journal:

Neuropsychiatric Disease and Treatment

13 May 2013

Number of times this article has been viewed

\author{
Naseem Akhtar Qureshi' \\ Abdullah Mohammed \\ Al-Bedah ${ }^{2}$ \\ 'General Administration for Research \\ and Studies, Sulaimania Medical \\ Complex, ${ }^{2}$ National Center for \\ Complementary and Alternative \\ Medicine, Ministry of Health, Riyadh, \\ Saudi Arabia
}

\begin{abstract}
Mood disorders are a major public health problem and are associated with considerable burden of disease, suicides, physical comorbidities, high economic costs, and poor quality of life. Approximately $30 \%-40 \%$ of patients with major depression have only a partial response to available pharmacological and psychotherapeutic interventions. Complementary and alternative medicine (CAM) has been used either alone or in combination with conventional therapies in patients with mood disorders. This review of the literature examines evidencebased data on the use of CAM in mood disorders. A search of the PubMed, Medline, Google Scholar, and Quertile databases using keywords was conducted, and relevant articles published in the English language in the peer-reviewed journals over the past two decades were retrieved. Evidence-based data suggest that light therapy, St John's wort, Rhodiola rosea, omega-3 fatty acids, yoga, acupuncture, mindfulness therapies, exercise, sleep deprivation, and S-adenosylmethionine are effective in the treatment of mood disorders. Clinical trials of vitamin B complex, vitamin D, and methylfolate found that, while these were useful in physical illness, results were equivocal in patients with mood disorders. Studies support the adjunctive role of omega-3 fatty acids, eicosapentaenoic acid, and docosahexaenoic acid in unipolar and bipolar depression, although manic symptoms are not affected and higher doses are required in patients with resistant bipolar depression and rapid cycling. Omega-3 fatty acids are useful in pregnant women with major depression, and have no adverse effects on the fetus. Choline, inositol, 5-hydroxy-L-tryptophan, and $\mathrm{N}$-acetylcysteine are effective adjuncts in bipolar patients. Dehydroepiandrosterone is effective both in bipolar depression and depression in the setting of comorbid physical disease, although doses should be titrated to avoid adverse effects. Ayurvedic and homeopathic therapies have the potential to improve symptoms of depression, although larger controlled trials are needed. Mind-body-spirit and integrative medicine approaches can be used effectively in mild to moderate depression and in treatment-resistant depression. Currently, although CAM therapies are not the primary treatment of mood disorders, level 1 evidence could emerge in the future showing that such treatments are effective.
\end{abstract}

Keywords: complementary and alternative medicine, mood disorders, Ayurveda, homeopathy, integrative medicine

\section{Introduction}

Treating mood disorders has become complex, given the many changes over the years in epidemiological trends, etiological models, classification systems and symptom clusters, diagnosis and diagnostic tools, types of interventions, and outcome studies. Despite psychopharmacological advances during the past six decades, the management of major depression and other mood disorders continues to challenge mental health providers.
Qureshi

General Administration for Research and Studies, Sulaimania Medical Complex, PO Box 2775, Riyadh III76, Saudi Arabia

Tel +96 6I 4735038

Email qureshinaseem@live.com 
Many patients with mood disorders who are dissatisfied with conventional treatment seek other interventions, in particular complementary and alternative medicine (CAM). In general, CAM is safe and cost-effective, has limited comparative efficacy to modern allopathic treatments, and is well tolerated by patients with physical and mental disorders. ${ }^{1}$ This evidence-based review summarizes recent advances in the use of CAM for mood disorders, mainly in the adult population.

\section{Literature search}

A search of the PubMed, Medline, Google Scholar, and Quertile databases was done using the key phrases "complementary and alternative medicine" and "integrative medicine combined with mood disorders and major depression", and relevant articles published over the past two decades (1992-2012) in the peer-reviewed English language journals were retrieved. Other keywords, including "botanicals", "phytomedicine", "nutrients", "herbs", "dietary supplements", "vitamins", "fatty acids", "folate", "hormones", "exercise", "meditation", "yoga", "Ayurveda", "homeopathy", and "mindbody-spirit" were combined with "major depression" and "mood disorders" for more specific searches. More than 30,000 articles were retrieved using this method. Many articles were excluded, including articles without abstracts $(n=529)$, papers not published in the English language $(n=840)$, full articles not being available $(n=215)$, and duplication of articles across searches $(n=12,120)$, along with many papers unrelated to the topic under consideration $(n=16,046)$. Only 250 papers were retained for further review. Thirty-seven articles that described single cases and small case series (less than five subjects) were also excluded. In total, the authors selected 213 articles, which included open-label clinical trials, randomized controlled trials, systematic reviews, and metaanalyses addressing use of CAM in the management of major depression and other mood disorders. Eight references were added during revisions of this manuscript and one citation was deleted (see Figure 1).

\section{Mood disorders}

Mood disorders are common mental health problems, afflicting 154 million people around the world. ${ }^{2}$ Major depression is currently the third leading cause of disability worldwide. Major depression is preferentially associated with female gender, with manic disorders distributed equally between males and females. Major depression is more common among people of low socioeconomic status, those with low education, those who are unmarried, separated, or divorced, those from a rural background, and those without intact families. ${ }^{3}$ Major depression has adverse consequences, including increased absenteeism from work, reduced productivity, disruption of family life, and increased health care utilization and costs. Smoking, drug abuse, sexual dysfunction, crime, violence, and suicidal behavior are further consequences for many sufferers. ${ }^{4-6}$ In addition, mood disorders are the most common cause of premature mortality, acceleration of aging, and reduced life expectancy. ${ }^{7}$

Mood disorders exist in many forms, including unipolar depression, bipolar depression, mania, mixed syndromes, and subsyndromes, and these conditions can co-occur with other psychiatric and physical disorders. ${ }^{8-10}$ Comorbid conditions complicate not only the diagnosis but also the management, prognosis, and outcome of major depression. ${ }^{11}$

Psychopharmacological and nondrug therapies are effective in many patients with mood disorders. However, $30 \%-40 \%$ of patients with major depression become resistant to these treatments as a result of medical comorbidity, unavailability of appropriate services, and poor adherence with available therapies. These difficult-to-treat patients need specialized treatment strategies. ${ }^{12,13}$ The two major classifications of mental disorders provide a comprehensive view of mood disorders, but these have now been divided into more than 30 diagnostic categories. ${ }^{14,15}$ Major depression has a definite onset, is strongly influenced by biological and psychosocial factors, ${ }^{3,16,17}$ and is also related to personality disorders. ${ }^{18}$ Preclinical studies in animals and basic neurobiological research in human subjects have provided biological insights into the pathogenesis of major depression, and have helped in the development of drugs now used in major depression and other mood disorders. ${ }^{19,20}$

Nondrug interventions have also been developed to treat major depression, in view of the influence of psychosocial factors. ${ }^{21}$ Dacher described four healing systems, ie, homeostatic, conventional, mind-body, and spiritual. ${ }^{21}$ Sarris has also described an antidepressant-lifestyle-psychological-social model for treating depression that integrates conventional drug treatments with CAM, lifestyle changes, and psychosocial techniques. $^{22}$ A combination of biological and psychosocial treatment produces better outcomes and reduces the rates of relapse and suicide. ${ }^{23}$ From a psychopharmacological perspective, there have been many controlled trials in mood disorders consistently reporting that $30 \%$ of patients achieve full remission, 30\% are partial responders, and the rest are nonresponders. ${ }^{24,25}$ However, application of these results in the 


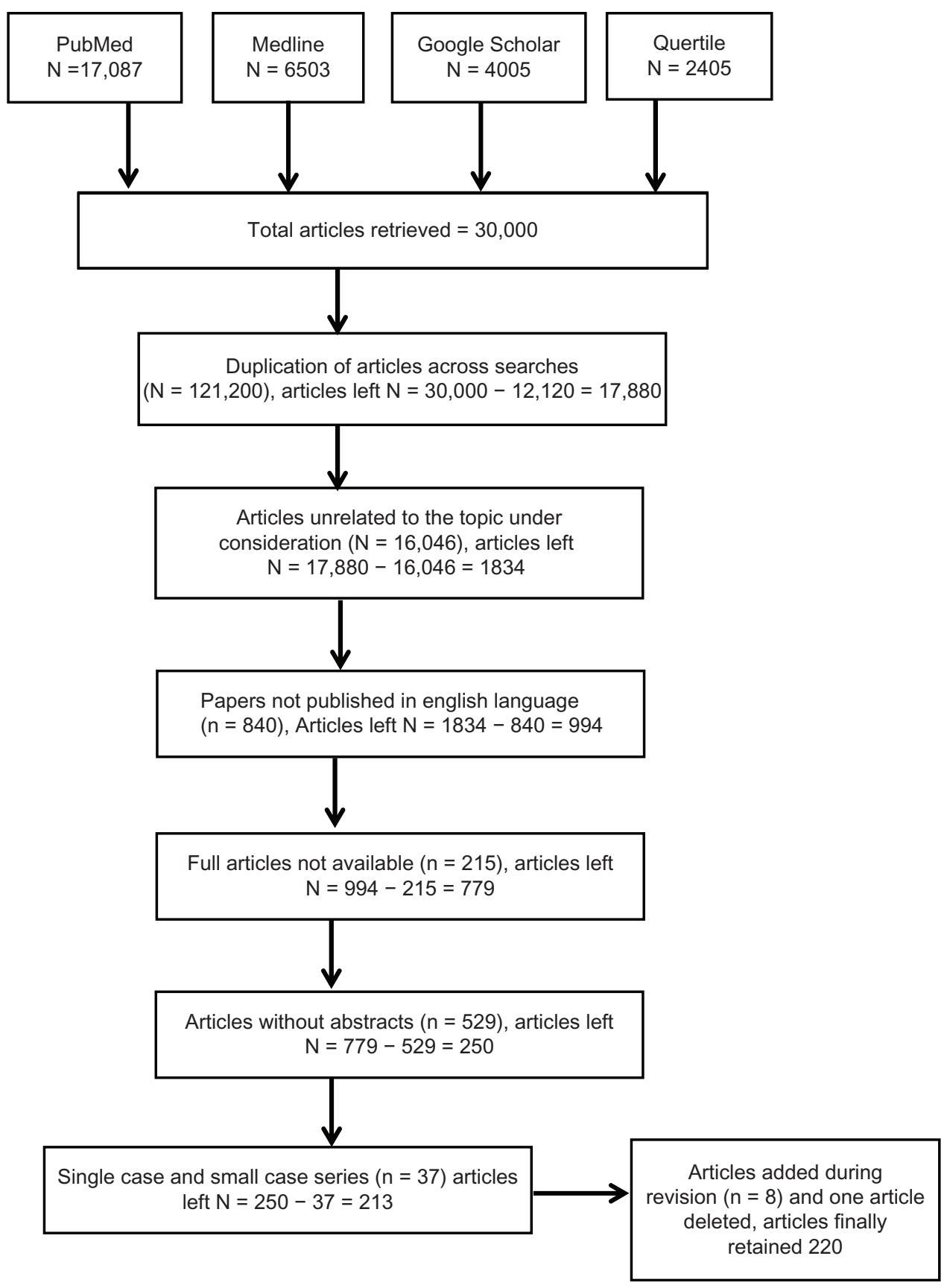

Figure I Literature search.

real-world setting is problematic because of the criteria used to select patients for entry into these trials. In a naturalistic study of 4000 patients with chronic depression and comorbid psychiatric or medical conditions treated with citalopram up to $60 \mathrm{mg} /$ day, the remission rate was $27 \%$ and the response rate was $47 \%$. When nonresponders were augmented or switched to another antidepressant, $30 \%$ remitted..$^{26}$ According to Bambauer et al, patients with treatment-resistant depression attributable to nonadherence with medication ${ }^{27}$ need augmentation strategies. ${ }^{12,13}$ Patients with treatment-resistant depression are also at higher risk for relapse..$^{28,29}$

\section{Complementary and alternative medicine}

Increasing attention is being paid worldwide to more traditional medical systems, including Ayurveda, yoga, naturopathy, Unani medicine, Siddha, and homeopathy. ${ }^{30}$ Use of CAM therapies in various illnesses is on the rise. ${ }^{31}$ 
Table I Complementary and alternative treatment modalities ${ }^{34-36}$

\begin{tabular}{|c|c|c|}
\hline Aromatic therapy (B) & Prophetic medicine (S) & Acupuncture (B) \\
\hline Ayurveda (B) & Islamic medicine $(\mathrm{S})$ & Aikido (B) \\
\hline Chiropractic therapy (B) & Cupping therapy (B) & Biochemics (B) \\
\hline Touch therapy (B) & Laser therapy (B) & Bioelectromagnetic (B) \\
\hline Arabic-Hakim medicine (B) & Moxa therapy (B) & Chiropody (B) \\
\hline Lymphatic drainage massage (B) & Polar therapy (B) & Absent healing $(\mathrm{S})$ \\
\hline Reflexology (B) & Bach's flower therapy & Contact healing (S) \\
\hline Homeopathy (B) & Macrobiotic diet therapy (B) & Dance therapy (B) \\
\hline Ionic therapy (B) & Bates exercise (B) & Eckankar (S) \\
\hline Rising sun physical therapy (B) & Air therapy (B) & Mind power $(S)$ \\
\hline Shiatsu (Japanese massage) (B) & Mineral water therapy (B) & Palmistry (S) \\
\hline Camel milk and urine therapy (B) & Hypnosis (M) & Paradox therapy (S) \\
\hline Uncooked foods therapy (B) & Yoga (B) & Structural integration (B) \\
\hline Tai chi (B) & Herbal medicine (B) & Tantric medicine $(\mathrm{B})$ \\
\hline Faith therapy $(S)$ & Fasting (B) & Lotte Berk method (B) \\
\hline Reiki massage (B) & Hobbies therapy (B) & Lakhovsky oscillatory coils (B) \\
\hline Spiritual healing (S) & Energy therapy (B) & Ionization (B) \\
\hline Healthy nutrition therapy (B) & Ozone therapy (B) & Sleep therapy (B) \\
\hline Healing by steam bath, sauna (B) & Water spraying (B) & Homeopathy (B) \\
\hline Laughing therapy (B) & Visualization therapy (M) & Gravitonics (B) \\
\hline Dream therapy $(\mathrm{M})$ & Biorecovery therapy (B) & Feldenkrais (B) \\
\hline Honey therapy (B) & Pyramidal energy (B) & Autosuggestion (M) \\
\hline Bee sting therapy (B) & Bee product therapy (B) & Apple cider vinegar and honey (B) \\
\hline Vitamin therapy (B) & Intuition sciences (M) & Alexander method (B) \\
\hline Iriodology (B) & Chiropractic therapy (B) & Adlerian analysis (M) \\
\hline Mineral therapy (B) & Natural therapy $(\mathrm{M})$ & Alexandrian analysis (M) \\
\hline Cauterization (B) & Bone setting (B) & Astrology (M) \\
\hline Cellular mineral therapy (B) & Medical massage (B) & Bioenergetics (B) \\
\hline Osteopathy (B) & Chiropractic skull therapy (B) & Biofeedback training (B) \\
\hline Art therapy (M) & Traditional Chinese medicine (B) & Direct decision therapy (M) \\
\hline Insect therapy (M) & Color therapy (M) & Ericksonian analysis (M) \\
\hline Clay therapy (M) & Zen macrobiotics (B) & Existential analysis (M) \\
\hline Frommian analysis $(\mathrm{M})$ & Gestalt therapy $(M)$ & Graphology (B) \\
\hline Polarity therapy (M) & Sex therapy (M) & Hornevian therapy (M) \\
\hline Rediesthesia (M) & Enlightened healing (S) & Imagery therapy (M) \\
\hline Reich's orgone therapy (M) & Evangelistic healing (S) & Jungian analysis (M) \\
\hline Rikli's sunshine cure $(\mathrm{M})$ & Paradox therapy (S) & Logotherapy (M) \\
\hline Rationale therapy $(\mathrm{S})$ & Pecci-Hoffman's therapy (S) & Maslovian analysis (M) \\
\hline Scientology (S) & Primal therapy (S) & Mensendick system (M) \\
\hline Spiritualists (S) & Rankian therapy (M) & Napropathy (B) \\
\hline \multirow[t]{2}{*}{ Sullivanian analysis (M) } & Transactional analysis (M) & Phrenology (B) \\
\hline & Zen (S) & Phrenosophical spiritual healing (S) \\
\hline
\end{tabular}

Note: Many of these therapies overlap mind (M), body (B), and spirit (S) concepts.

Perron et al found that barriers to conventional treatment have contributed to the increased use of CAM in mentally ill patients. ${ }^{31}$ Another study found that use of CAM was unaffected by the perceived effectiveness of conventional treatment or compliance with medication among persons with bipolar disorder. ${ }^{32}$ There are now more than 120 CAM treatments available (Table 1), all of which involve body, mind, and spiritual concepts. This classification of various therapies, and designated by mind, body, or spirit, is perceived as strict compartmentalization, but many of the therapies mentioned have double or triple designations in terms of our theoretical understanding of diagnosis, treatment, and causal mechanisms. Another reason for increasing use of CAM is the positive findings of studies in patients with major depression. ${ }^{33}$ Many clinical trials of CAM are presently under way worldwide, and are expected to yield positive results in patients with major depression and other mood disorders.

\section{Role of CAM in mood disorders}

Complementary and alternative medicine is the most practiced but least researched form of treatment because of the complexities inherent in assessment of its effectiveness 
in major depression and other mood disorders. These complexities include solo versus adjunctive treatments, the multiple facets of depression, design and methodological issues, and use of herbs with unknown bioactive ingredients. To address this conundrum, the Canadian Network Group has developed guidelines for the use of CAM in adults with major depression, suggesting efficacy using light therapy for seasonal affective disorder, St John's wort for mild to moderate depression (level 1 evidence), and omega-3 fatty acids, yoga, exercise, sleep deprivation, and S-adenosylmethionine for major depression. ${ }^{37}$ Level 1 evidence is that obtained from at least one appropriately designed randomized controlled trial. The American Task Force has also reported promising results with regard to omega-3 fatty acids, St John's wort, folate, S-adenosylmethionine, acupuncture, light therapy, exercise, and mindfulness psychotherapies in major depression. ${ }^{38}$ This report recommends the undertaking of more rigorous and larger studies in the future, and that each CAM treatment must be evaluated separately in adequately powered controlled trials. They suggested that further focus is needed on clinical, research, and educational initiatives with regard to CAM in psychiatry, and cautions that the greatest risk of pursuing CAM is possible delayed use of other well established treatments. ${ }^{38}$ Dutch researchers have also developed a protocol for ensuring safe and effective use of CAM in the mental health setting. ${ }^{39}$

\section{Dietary supplements as CAM therapies}

Over-the-counter dietary supplements (nutraceuticals) are used extensively by patients with depression, and are categorized as nutrients, herbal and dietary supplements, and traditional and nontraditional methods. ${ }^{40}$ Nutraceuticals have also been used to promote mental and physical health, to prevent illness, and to treat diseases, with substantial benefits. ${ }^{40}$ Nutraceuticals, in particular S-adenosylmethionine, have benefited patients with major depression and other mood disorders. This compound provides methyl and sulfate groups used in the synthesis of deoxyribonucleic acid, proteins, phospholipids, neurotransmitters, and the antioxidant, glutathione, that are disturbed in people with mood disorders. ${ }^{41}$ In a critical review of the literature, Brown et al reported the results of 48 studies and found $\mathrm{S}$-adenosylmethionine to be safe and effective for the treatment of depression. ${ }^{42} \mathrm{~A}$ recent review further supports the use of this compound in mild-to-moderate depression, reporting that eight of 14 studies $(57 \%)$ produced positive results. ${ }^{43}$ Interestingly, like selective serotonin reuptake inhibitors (SSRIs), neither S-adenosylmethionine nor St John's wort have been associated with an increased risk of suicide. ${ }^{43}$ Several researchers have appraised the clinical and pharmacological benefits of S-adenosylmethionine in depression and as an adjunct in treatment-resistant depression. ${ }^{44-46}$ In a double-blind randomized study of patients with depression who were nonresponders to SSRIs, Papakostas et al reported preliminary beneficial effects from S-adenosylmethionine augmentation with good tolerability. S-adenosylmethionine appears to be a safe adjunctive treatment for patients with major depression who do not respond to SSRIs, but this needs confirmation in clinical trials. ${ }^{47}$ S-adenosylmethionine alone or combined with other supplements has been shown to alleviate depression associated with musculoskeletal disease, ${ }^{48,49}$ liver disease, ${ }^{50,51}$ Parkinson's disease, ${ }^{52}$ and human immunodeficiency virus/acquired immune deficiency syndrome. ${ }^{53} \mathrm{~S}$-adenosylmethionine acts similarly to noradrenergic antidepressants, but with fewer side effects. ${ }^{44}$

In a randomized clinical study of 30 women with postpartum depression, $1600 \mathrm{mg}$ /day of S-adenosylmethionine resulted in a $70 \%$ reduction in symptoms of depression and anxiety compared with a $50 \%$ reduction in the placebo group by day $30 .{ }^{54} \mathrm{~S}$-adenosylmethionine is safe to use during pregnancy and breast-feeding. Infants naturally have 3-7 times higher S-adenosylmethionine levels than adults. ${ }^{55}$ This is because they need more $\mathrm{S}$-adenosylmethionine for methylation of the developing brain, especially the myelin sheaths critical for conduction of electrical impulses. A secondary analysis of clinical trial data for S-adenosylmethionine administered to patients with major depression nonresponsive to SSRIs found a positive impact on symptoms of depression and related cognitive dysfunction. ${ }^{56}$ In summary, the primary and adjunctive role of S-adenosylmethionine in patients with major and treatment-resistant depression is gaining solid ground.

\section{Herbs and mood disorders}

Numerous herbs are known to contain bioactive substances, although the clinical significance of these needs further investigation. ${ }^{57}$ Research in phytomedicine has been generating considerable amounts of new data on the chemical, pharmacological, and clinical aspects of herbs in mood disorders. ${ }^{58,59}$

\section{St John's wort}

St John's wort contains two bioactive substances, ie, hyperforin and hypericin, and has been used effectively in the treatment of major depression. ${ }^{57}$ Although initial reports of its use 
were hampered by inadequate concentrations of hyperforin, ${ }^{60}$ subsequent comparative, randomized, double-blind, placebocontrolled trials using better standardized St John's wort (Kira ${ }^{\circledR}$ [LI-160 extract], 1800 mg/day, Klosterfrau Healthcare Group, Germany; Remotiv ${ }^{\circledR}$, Flordis Natural Medicines, Australia; or Ze $117^{\circledR}, 500$ mg/day Zeller AG, Switzerland) found it to be as effective as imipramine $150 \mathrm{mg}$ /day and fluoxetine $20 \mathrm{mg} /$ day for all severity levels of depression, but with fewer gastrointestinal side effects. ${ }^{61,62} \mathrm{~A}$ widely cited randomized, multicenter, placebo-controlled study of inpatients with depression given St John's wort Kira ${ }^{\circledR}$ (LI-160 extract) $900 \mathrm{mg} /$ day for 4 weeks, then increased to $1200 \mathrm{mg} /$ day for another 4 weeks, found Kira $^{\circledR}$ (LI-160 extract) to be no better than placebo. However, this negative result could be explained by the use of subtherapeutic doses of the bioactive substances in St John's wort. ${ }^{63}$ The greater severity and resistant nature of depression might also have contributed to lack of effectiveness, but this is unlikely, given the results from Phase II of the study. ${ }^{64}$ In another study of severely depressed patients given $\operatorname{Kira}^{\circledR}$ (LI-160, 900-1500 mg/day), sertraline (50-100 mg/day), or placebo, found that neither sertraline nor St John's wort showed more efficacy than placebo. ${ }^{65}$ In a randomized, placebo-controlled multicenter study of outpatients with mild-to-moderate depression, Kira ${ }^{\circledR}$ (LI-160 extract) and fluoxetine did not differ significantly with regard to efficacy measures except for remission rates (24\% for Kira ${ }^{\circledR}$ [LI-160 extract], 28\% for fluoxetine, and 7\% for placebo). It was concluded that $\mathrm{Kira}^{\circledR}$ (LI-160 extract) and fluoxetine were no more effective than placebo in the short-term treatment of mild-to-moderate depression. ${ }^{66}$ The results of this study are supported by other researchers. ${ }^{67}$

In another randomized study of patients with major depression, Kira $^{\circledR}$ (LI-160 extract, $900 \mathrm{mg}$ /day) was more effective than fluoxetine $(20 \mathrm{mg} /$ day $)$ and showed a trend towards superiority over placebo. ${ }^{68}$ The remission rates were higher for Kira ${ }^{\circledR}$ (LI-160 extract) compared with fluoxetine and placebo. ${ }^{68} \mathrm{~A}$ reanalysis of earlier data suggested that patients' beliefs regarding treatment may have a stronger effect on clinical outcome than the actual medication received, depending on what treatment patients thought they were receiving and what they actually received.$^{69}$ Recent well controlled studies, meta-analyses, and consensus guidelines support the efficacy of St John's wort in patients with mild-to moderate-depression in particular. . $33,37,43,70,71^{-1}$

In another double-blind, randomized, placebo-controlled, long-term trial, Kasper et $\mathrm{al}^{70}$ reported the beneficial effects of Hypericum extract (WS ${ }^{\circledR} 5570$, Dr. Willmar Schwabe Pharmaceuticals, Germany) in adult outpatients who had recovered from an acute episode of moderate depression. Patients treated with WS ${ }^{\circledR} 5570$ showed more favorable time courses to resolution of symptoms and greater overall improvement than those randomized to placebo. Used as long-term maintenance therapy, $\mathrm{WS}^{\circledR} 5570$ was reported to have a prophylactic effect in patients with early-onset depression and in those with a high degree of chronicity. WS ${ }^{\circledR} 5570$ also showed a beneficial effect in preventing relapse after recovery from acute depression. ${ }^{70}$

St John's wort has also been used in primary care psychiatric settings and in patients with seasonal affective disorder, and examined with regard to relapse rates in those who responded, all with good results. For example, Szegedi et al reported that $71 \%$ of patients with moderate-to-severe depression treated in primary care responded to $900 \mathrm{mg} /$ day Hypericum extract $\mathrm{WS}^{\circledR} 5570$, and that $900-1800 \mathrm{mg} /$ day was as effective as paroxetine $20-40 \mathrm{mg} /$ day, but without side effects. ${ }^{72}$ Patients with mild seasonal affective disorder have also been reported to benefit from Kira ${ }^{\circledR}$ (LI-160 extract). ${ }^{37,73}$ With regard to relapse, reanalysis of data from 154 patients with mild-to-moderate depression treated with St John's wort (STW 3-VI; Laif ${ }^{\circledR}$, Steigerwald Arzneimittelwerk GmbH, Germany) 900 mg, citalopram $20 \mathrm{mg}$, or placebo once daily found that relapse rates were highest in the citalopram group, followed by the St John's wort and placebo groups, with no difference in the severity of relapse. ${ }^{74}$ Further, the duration of response was longest for the St John's wort group, intermediate for the citalopram group, and shortest for the placebo group. Researchers concluded that 3-VI had the longest duration of response and was more effective than citalopram and placebo in decreasing relapse and recurrence rates. ${ }^{74}$ However, in a 12 -week study of minor depression, St John's wort (Cederroth International, Sweden, $810 \mathrm{mg}$ /day) was not superior to citalopram $20 \mathrm{mg} /$ day or placebo, and the authors called for more research to identify better treatment options for patients with minor depression. ${ }^{75}$ In a review of commonly used botanicals in the treatment of anxiety and mood disorders, St John's wort (5 of 7 trials), black cohosh (all studies reviewed), and ginseng (1 trial) have been reported to improve symptoms of depression and anxiety in menopausal and postmenopausal women. ${ }^{76}$

St John's wort is generally used as a second-line option, except in women with a history of response to low doses of an SSRI. ${ }^{57}$ St John's wort has potential side effects that increase with higher doses. These include phototoxic rash, SSRI-like effects, serotonin syndrome, and induced mania. ${ }^{77}$ The side effect profile and dropout rates in the range of $0 \%-5.7 \%$ for patients receiving St John's wort are not different from placebo, and have been reported to be similar to those of tricyclic antidepressants and slightly lower than those of the SSRIs. ${ }^{77}$ A study that reanalyzed data from four clinical trials found that St John's wort extract (WS $\left.{ }^{\circledR} 5570\right)$ was associated 
with fewer adverse events than SSRIs. ${ }^{78}$ Nevertheless, St John's wort reduces circulating levels of a large number of drugs, including digoxin, warfarin, and oral contraceptives, because it induces cytochrome P450 (CYP) 3A4 and CYP 1A2 enzymes as well as P-glycoprotein in the intestinal wall. ${ }^{77,79}$ According to one study, the information available on websites selling St John's wort is not of good quality and consumers should bear this in mind when considering buying the product. ${ }^{80}$ Another study that evaluated safety information provided in the labeling of St John's wort products found that the majority of producers failed to address safety issues adequately. ${ }^{81}$ Health care providers and consumers will benefit if the US Food and Drug Administration and similar regulatory bodies elsewhere re-examine the labeling requirements for dietary supplements. ${ }^{81}$

\section{Rhodiola rosea}

The use of medicinal herbs had been widespread across many cultures since ancient times. A recent university student survey ${ }^{83}$ found that most herb use was self-prescribed (60\%) and undisclosed to health providers (75\%), 34\% of users took herbs to treat a mood disorder, $13 \%$ of herb users were taking concurrent prescription medication, and those who took both herbs and prescription medications had higher depression and anxiety scores than other herb users. Detailed patient interviews are necessary to prevent adverse herb-drug interactions. ${ }^{82}$

Rhodiola rosea, recommended in many conditions, including irregular menopause,,$^{83,84}$ has also been reported to

Table 2 Herbal medicinal products: contaminants and adverse effects $^{93-101}$

\begin{tabular}{ll}
\hline Contaminants & Adverse effects \\
\hline - Dust & - Agranulocytosis \\
- Pollens & - Meningitis \\
- Insects & - Multiorgan failure \\
- Rodents & - Perinatal stroke \\
- Parasites & - Arsenic \\
- Microbes & - Lead or mercury poisoning \\
- Fungi & - Malignancies or carcinomas \\
- Mould & - Hepatic encephalopathy \\
- Toxins & - Hepatorenal syndrome \\
- Pesticides & - Nephrotoxicity \\
- Mercury & - Rhabdomyolysis \\
- Cadmium & - Metabolic acidosis \\
- Chromium & - Renal or liver failure \\
- Lead & - Cerebral edema \\
- Arsenic and & - Coma \\
- Prescription drugs & - Intracerebral hemorrhage \\
& - Death \\
\hline
\end{tabular}

Note: *These contaminants were found mostly in herbal products originating in People's Republic of China, India, and the US. be effective in the treatment of mild-to-moderate depression. ${ }^{85}$ One trial used a standardized extract of Rhodiola rosea (SHR5, Swedish Herbal Institute, Sweden) at doses of $340 \mathrm{mg}$ and $680 \mathrm{mg}$ daily for six weeks with no reports of side effects. ${ }^{85}$ A systematic review has also supported the antidepressant effects of Rhodiola rosea. ${ }^{86}$ Its mechanism of action in major depression is thought to be via beta-endorphins, tryptophan, and serotonin in the brain..$^{57,88}$ Rosiridin is the bioactive ingredient of Rhodiola rosea, which is reported to inhibit monoamine oxidases $\mathrm{A}$ and $\mathrm{B}$ and may also be useful in dementia. ${ }^{83}$

Having no addictive potential, Rhodiola rosea is a mild stimulant, so should be taken in the morning to avoid sleep problems. It may induce temporary vivid dreams and mild nausea. It also binds with the estrogen receptor, so women with a personal or family history of estrogen-sensitive breast cancer should exercise caution in using Rhodiola rosea, although this issue needs further study. ${ }^{88}$ Products containing $3 \%$ rosavins and $1 \%$ salidrosides were found to be effective in a randomized controlled trial, and may be used to enhance the clinical effectiveness of Rhodiola rosea. ${ }^{57}$ Panossian et al provide detailed information on its traditional use, chemical composition, pharmacology, side effect profile, and clinical efficacy. ${ }^{84}$

\section{Saffron and other herbs}

A systematic review of herbs used in major depression and other mood disorders identified nine clinical trials that met all eligibility criteria. ${ }^{89}$ Three of these trials found saffron stigma extract to be more effective than placebo and equivalent in effect to fluoxetine and imipramine. Two studies found that saffron petal extract was significantly more effective than placebo and was equivalent to fluoxetine and saffron stigma extract. Lavender was found to be less effective than imipramine, but the combination of lavender and imipramine was significantly more effective than imipramine alone. When compared with placebo, Echium extract was found to decrease depression scores markedly at week 4 , although this effect had disappeared by week 6 . According to this review, saffron, lavender, Echium, and Rhodiola rosea when used alone or in combination with antidepressants showed good results in mild-to-moderate depression. ${ }^{89}$ Another critical review that identified 21 phytomedicines and 66 clinical trials involving 11 phytomedicines reported positive results of the aforementioned herbs in mild-to-moderate depression, anxiety, and sleep disorders. ${ }^{90}$ In a clinical trial of Free and Easy Wanderer Plus (FEWP, Golden Flower, People's Republic of China; a Chinese herbal extract formula), fluoxetine, and placebo, 150 patients with post-stroke depression showed significant improvement with both FEWP and fluoxetine compared with placebo. ${ }^{91}$ 
At the end of the trial, subjects on FEWP showed greater improvement than those on fluoxetine at week 2 and performed better than patients receiving fluoxetine in activities of daily living. This study suggests that FEWP can be used safely with few side effects in patients with post-stroke depression. ${ }^{91}$

Caution is important when using herbs and dietary supplements. Rai et $\mathrm{al}^{92}$ analyzed the heavy metal content in nine plant species used for the preparation of herbs in India and found that most samples had a heavy metal content exceeding the upper limits set by the World Health Organization. Further, heavy metals and organochlorine pesticides have been found in some dietary supplements in the US. ${ }^{93}$ In traditional Chinese medicine (Table 2), cases of heavy metal poisoning has been reported by several investigators. ${ }^{94}$ There is a large body of literature concerning the heavy metal content of herbal supplements used in CAM, including mercury, lead, chromium, cadmium, arsenic, cobalt, and pesticides, including dioxin. ${ }^{95-100}$ Quality control measures, including standardized doses and regulations, are needed for herbal products used for health reasons. ${ }^{40}$

\section{Vitamins in mood disorders}

Vitamins B and D, folate, and trace elements are essential for the functioning of neurons, and have been shown to afford protection against certain types of mental disorders, particularly depression. ${ }^{101}$ These nutrients become depleted in the body for many reasons, including poor nutrition, chronic disease, old age, stress, and polymorphism. Low vitamin B12, vitamin D, and folate levels are also associated with poor memory and cognitive dysfunction. ${ }^{102,103}$ Folic acid and folate from the diet are converted into L-methylfolate in the body. In a randomized, double-blind, placebo-controlled trial, 123 patients with major depression and schizophrenia maintained on standard psychotropic medications were given augmentation therapy of methylfolate $15 \mathrm{mg} /$ day or placebo. The investigators reported significant improvement in clinical and social symptoms with methylfolate compared with placebo. ${ }^{104}$ However, treatment with folate or vitamin B12 alone has been associated with mixed results in depression. Geriatric patients with depression and cognitive dysfunction showed benefit when tricyclic antidepressants were augmented with vitamin B complex (B1, B6, and B12) and folate. ${ }^{105}$ Nonresponse to antidepressants has been linked with low levels of folate. A study of 127 patients on fluoxetine supplemented with folate $400 \mathrm{mg} /$ day or placebo reported a $94 \%$ response rate to fluoxetine plus folate compared with a $61 \%$ response to fluoxetine plus placebo. ${ }^{106}$
However, a recent placebo-controlled study found little support for B12 (100 $\mu \mathrm{g} /$ day) with folate (400 $\mu \mathrm{g} /$ day) supplementation in community-dwelling adults already taking conventional antidepressants. ${ }^{107}$ Another placebocontrolled trial of folate plus vitamin B12 supplementation given to older patients with depression also yielded negative results. ${ }^{108}$

In summary, clinical trials of vitamin B and folate have yielded equivocal results in patients with major depression. Although methylfolate and vitamin B have favorable safety profiles, allergic reactions may occur using these substances. Folate and vitamin B reduce homocysteine levels, so may be cardioprotective. However, combination of these vitamins may cause restenosis of stents in men by stimulating endothelial proliferation, although this effect has not been seen in women. ${ }^{109}$

Low levels of vitamin D have been identified in patients with major depressive and other mood disorders, but vitamin D supplementation in these patients has produced inconsistent results. ${ }^{110}$ Supplemental use of vitamin D (800 International Units; IU) produced no positive results in a study of prevention of winter-time blues in elderly women. ${ }^{111}$ In a placebo- controlled study, obese men and women with major depressive disorder were given high doses of vitamin D (20,000 or 40,000 IU) or placebo per week for one year. Depression scores were higher in patients with low serum 25-hydroxyvitamin D ( $<40 \mathrm{nmol} \mathrm{L})$ levels than in those with normal levels of 25-hydroxyvitamin D ( $\geq 40 \mathrm{nmol} \mathrm{L}$ ), and participants given the vitamin D supplement showed significant improvement in depression compared with those in the placebo group. ${ }^{112}$ However, a recent placebo-controlled study of vitamin D3 supplementation in patients with low or high levels of 25-hydroxyvitamin D found that levels of 25-hydroxyvitamin D was significantly lower in patients with depression and that supplementation with vitamin D3 was not associated with improvement in symptoms compared with placebo. ${ }^{113}$ Similarly negative results were reported for another placebo-controlled trial in elderly women with symptoms of depression given vitamin D3 supplementation at $400 \mathrm{IU} /$ day and calcium. ${ }^{114}$ However, a recent review suggests that the suicide risk associated with vitamin $\mathrm{D}$ deficiency might be reduced by supplementation with vitamin D. ${ }^{115}$

Other nutrients commonly used in CAM include omega-3 fatty acids, choline, 5-hydroxy-L-tryptophan, inositol, and $N$-acetylcysteine. These substances are important in functioning of the neural networks involved in mood regulation. 


\section{Omega-3 fatty acids in mood disorders}

Fish-derived omega-3 fatty acids provide eicosapentaenoic acid (EPA) and docosahexaenoic acid (DHA), which help to maintain fluidity of the cell membrane, reduce inflammatory eicosanoids, and prevent the release of proinflammatory cytokines. ${ }^{57,116}$ Alpha linoleic acid also converts differentially into omega-3 fatty acids, EPA, and DHA. However, omega-6 fatty acids from domesticated animals and cultivated vegetables is consumed in much larger quantities than omega-3 fatty acids. Therefore, cell membranes acquire increasing proportions of omega- 6 fatty acids that adversely affect membrane fluidity and flexibility. ${ }^{57,116}$ In contrast, supplementation of omega-3 fatty acids from fish oil in liquid or capsule form maintains cell membrane fluidity. Substitution of omega- 6 fatty acids for omega- 3 fatty acids in the cell membrane has been associated with unipolar and bipolar depression, which is thought to be due to loss of membrane fluidity and flexibility. The latter results in disturbance of membrane proteins, such as enzymes, receptors, ion channels, and neurotransmitters, which in turn increases levels of inflammatory eicosanoids and proinflammatory cytokines. ${ }^{57,116} \mathrm{In}$ fact, a study of 12 women with bipolar disorder found that those treated with omega-3 fatty acid supplements showed significant improvement in membrane fluidity and flexibility. ${ }^{116}$ However, a review of the relevant literature on use of omega- 3 fatty acids in depression yielded mixed results, although this could have been due to methodological differences between studies, the lower proportions of EPA and DHA used in those studies, and patient selection bias. ${ }^{117}$ In another review of 19 relevant studies, 13 reported a positive effect of omega- 3 fatty acids in patients with depression, whereas six studies found no such association. ${ }^{118}$ In addition, a meta-analysis of relevant studies reported that $>60 \%$ EPA (out of the total of EPA and DHA, where dose range of 200-2200 mg/day of EPA in excess of DHA) had a positive impact on symptoms of depression compared with studies that used doses containing $<60 \%$ of total EPA and DHA. ${ }^{119}$ Finally, a placebo-controlled trial of adding omega-3 fatty acids to citalopram in patients with depression found significant improvement in depression scores compared with a placebo plus citalopram group, although there was no improvement in the speed of the initial antidepressant response. ${ }^{120}$

An increased risk of suicide, commonly associated with depression, has been linked with omega-3 fatty acid deficiency. ${ }^{121}$ A case-controlled study at autopsy compared omega-3 fatty acid levels in the orbitofrontal cortex of patients with major depressive disorder $(\mathrm{n}=15)$ and agematched controls $(n=27)$. Lower DHA levels were found in the orbitofrontal cortex of $32 \%$ of female patients and $16 \%$ in male patients, ${ }^{122}$ suggesting that lower levels of DHA could be a marker of increased suicide risk in patients with depression. Several other clinical trials support the adjunctive role of EPA and DHA in the treatment of both unipolar and bipolar depression. ${ }^{123-125}$ Omega-3 fatty acids are both safe during infant development and effective for the treatment of major depression in pregnant women. Notably, low fish consumption and omega-3 fatty acids have been linked with depression more in women than in men. ${ }^{126}$ Finally, a placebocontrolled study of 45 patients with bipolar disorder given omega- 3 fatty acids \pm cytidine found no significant effect on symptoms of depression compared with the placebo group. ${ }^{127}$ Cytidine, a pyrimidine, was reported to have antidepressantlike effects in preclinical studies. In summary, further research is needed before recommending use of omega-3 fatty acids as monotherapy in patients with major depressive and other mood disorders.

Omega-3 fatty acids also have a preventive role. Interestingly, a lower lifetime prevalence of bipolar II disorder has been associated with greater consumption of seafood. ${ }^{128,129}$ Further, a small open-label study of bipolar I patients $(n=10)$ who were given EPA at a daily dose of 1.5-2.5 g found that eight of ten (80\%) had a 50\% decrease in depression scores. ${ }^{130}$ Subsequently, a randomized controlled trial has substantiated the adjunctive role of omega-3 fatty acids (6.2 g EPA plus $3.4 \mathrm{mg}$ DHA and $1-2 \mathrm{~g}$ ethyl-EPA) in patients with bipolar II disorder receiving conventional mood stabilizers. ${ }^{131}$ A randomized controlled study of patients with bipolar disorder and rapid cycling who were receiving conventional treatment found that those given EPA $6 \mathrm{mg} /$ day showed no significant difference in depressive or manic symptoms after four months of intervention than the group receiving placebo. ${ }^{132}$ These negative results might be due to the use of EPA without DHA and inclusion of patients with resistant rapid cycling. Thus, patients with dysphoria and rapid cycling should be given higher doses of EPA and DHA, probably 8-10 g/day. ${ }^{133}$ A recent metaanalysis of five pooled databases related to use of omega-3 fatty acids in bipolar patients found a significant reduction in symptoms of depression, although scores for mania were unaffected, thus supporting the adjunctive role of omega-3 fatty acids in the treatment of symptoms of depression in bipolar patients. ${ }^{134}$

Pregnant women often have depleted omega- 3 fatty acid stores and are at higher risk for postpartum depression and 
bipolar depression. ${ }^{135}$ Almost all psychotropic medications carry a risk of side effects in pregnant women and may also adversely affect fetal and infant development. CAM therapies are safe alternatives in pregnant women with major depression. In randomized studies that used fixed doses ${ }^{136}$ or a range of doses $\left(0.5,1.4,2.8 \mathrm{~g}\right.$ /day) with no placebo controls, ${ }^{137} \mathrm{EPA}$ and DHA (3-8 g/day) were found to be effective in pregnant women with major depression and postpartum depression, with no adverse effects on the fetus. However, researchers have suggested that these studies of omega-3 fatty acids need to be repeated in a larger sample of pregnant women with depression. ${ }^{136-137}$ S-adenosylmethionine, St John's wort, bright light therapy, acupuncture, and exercise have also been reported to improve symptoms of depression in women. ${ }^{138}$ Further studies are needed to delineate specific CAM therapies useful in premenstrual syndrome, premenstrual dysphoric disorder, antepartum and postpartum depression, lactation, and transition through menopause. ${ }^{138-139}$

Omega-3 fatty acids are also safe for use in children and adolescents with bipolar disorder. An 8-week open-label study of 20 children (aged 6-16 years) with bipolar disorder given EPA $1290 \mathrm{mg}$ /day and DHA $4300 \mathrm{mg} /$ day found that $35 \%$ of children had more than a 50\% decrease in Young Mania rating scores, ${ }^{140}$ consistent with results in pediatric depression. ${ }^{141}$ Two-thirds of patients did not show improvement, indicating that omega-3 fatty acids are ineffective in pediatric bipolar disorder. However, larger studies are needed to confirm this. Pediatric bipolar disorder is a difficult condition to treat, and some pediatric bipolar patients may benefit from CAM therapies. One review has reported that omega-3 fatty acids and lecithin/choline have potential utility as CAM in pediatric bipolar disorder. S-adenosylmethionine and inositol have some data supporting their efficacy in the treatment of depressive symptoms. Some data suggest these compounds may be useful adjunctive treatments, but few data are available to support their use as stand-alone therapy in pediatric bipolar disorder. ${ }^{142}$ Another small open-label trial of a multinutrient supplement (EMPower ${ }^{\mathrm{TM}}$ ) found that $70 \%$ of pediatric completers with bipolar spectrum disorder demonstrated a significant decrease in both depression and mania scores between baseline and the final visit $(P<0.05)$. Gastric discomfort was the only reported side effect. These researchers suggested that randomized, placebo-controlled trials of EMPower are warranted and feasible. ${ }^{143}$ Evidently, omega-3 fatty acid treatment was associated with a very modest improvement in symptoms of mania in children with bipolar disorder. The most commonly observed side effects of omega-3 fatty acids in children are nausea, heartburn, stomach pain, belching, bloating, and diarrhea attributable to higher doses and use of unrefined fish oil preparations. Bleeding episodes due to reduction in platelet aggregation and triggering of mania are other side effects of high doses of omega-3 fatty acids. Use of omega-3 fatty acids should be strictly avoided in patients on anticoagulant therapy and antidiabetic medications. Some omega-3 fatty acids found in fish oil can increase low-density lipoprotein cholesterol, which is bad for the heart. ${ }^{57}$

\section{Choline in bipolar disorder}

Choline has been used effectively in ameliorating symptoms of mania. A small, open-label study of six patients with treatment-resistant rapid cycling bipolar disorder and stabilized on lithium found that addition of free choline 2000-7200 mg/day resulted in improvement of manic symptoms, although the impact on depression was variable. ${ }^{144}$ A randomized controlled trial of oral choline in rapid cycling bipolar patients treated with lithium reported significantly decreased purine levels in the brain over a 12-week period, which was related to the anti-manic effects of choline. ${ }^{145}$ Oral administration of exogenous choline increased synthesis of phospholipids in the cell membrane and corrected the mitochondrial component of diathesis in patients with bipolar disorder inadequately meeting the demand for increased adenosine triphosphate production. ${ }^{145}$ Thus, choline supplementation in small studies was effective for improving manic symptoms in bipolar patients, although larger studies are needed before recommending use of oral choline in the treatment of mania in bipolar I disorder.

\section{Inositol in bipolar disorder}

Inositol, a glucose isomer precursor of phosphatidyl inositol linked to the second messenger system, has been found to be more effective than placebo in the treatment of depression and other psychiatric illnesses, including panic disorder. Doses in the relevant studies have ranged from 12,000 to $20,000 \mathrm{mg} /$ day. ${ }^{146}$ Inositol, a vitamin-like substance found in many plants and animals, can be produced synthetically. A randomized controlled trial in 24 bipolar patients given inositol or placebo found no significant differences between the treatment groups. However, a trend towards improvement on inositol led researchers to recommend that larger studies be performed. ${ }^{147-148}$ Another study of 66 bipolar I or II patients with resistant depression examined the benefits of augmenting mood stabilizers with lamotrigine, inositol, or risperidone, and found that the rate of recovery was $23.8 \%$ with lamotrigine, $17.4 \%$ with inositol, and $4.6 \%$ with risperidone. ${ }^{149}$ Nierenberg et al 
suggested that patients with treatment-resistant depression are suitable candidates for inositol augmentation. However, at therapeutic doses, inositol frequently causes flatulence and occasionally induces mania. ${ }^{149}$

\section{5-hydroxy-L-tryptophan in bipolar disorder}

5-hydroxy-L-tryptophan is an immediate precursor in the synthesis of serotonin, and deficiency of serotonin can cause major depression. As a dietary supplement, 5-hydroxy-Ltryptophan is used widely as a self-medication for depression, and has replaced L-tryptophan, which caused eosinophilia myalgia syndrome and was taken off the market. ${ }^{150}$ Use of L-tryptophan and Showa Denko KK have been shown to be the main causes of this syndrome, but 5-hydroxy-Ltryptophan is not associated with such toxicity. ${ }^{150}$ There is some (albeit limited) support for 5-hydroxy-L-tryptophan 200-300 mg/day being more effective than placebo when given alone in adults with major depression, although the data are better when it is used to augment antidepressants. ${ }^{151}$ The most common side effects include nausea, vomiting, diarrhea, headache, and insomnia. No case of serotonin syndrome has been reported in subjects taking 5-hydroxy-Ltryptophan alone or in combination with SSRIs. Further, no adverse interactions have been reported between 5-hydroxyL-tryptophan and the monoamine oxidase inhibitors. ${ }^{152}$ In their review, Sarris et al found that use of omega-3 fatty acids, S-adenosylmethionine, folic acid, 5-hydroxy-L-tryptophan, inositol, lavender, and traditional Chinese medicines were effective when used to supplement antidepressants and mood stabilizers in mood disorders. ${ }^{134}$

\section{$\mathbf{N}$-acetylcysteine in bipolar disorder}

$\mathrm{N}$-acetylcysteine, a precursor of glutathione, is an important antioxidant in the brain and reduces oxidative stress. Increased oxidative stress and altered glutathione metabolism have been reported in bipolar and major depressive disorder. ${ }^{153}$ A randomized controlled trial in bipolar patients on mood stabilizers found that those who were given

Table 3 Treatment options in Ayurvedic medicine

\begin{tabular}{ll}
\hline Diet & Yoga practices \\
Lifestyle changes & Herbal preparations \\
Herbs, spices & Cleansings \\
Avoidance of risk/aggravating factors & Use of immunomodulators \\
Psychotherapy & Rejuvenation medicines \\
Massage & Palliative treatments \\
Meditation & Panchakarma detoxification \\
\hline
\end{tabular}

adjunctive $N$-acetylcysteine $2 \mathrm{~g}$ /day showed a significant improvement in depression, mania, quality of life, and social and occupational functioning compared with placebo. ${ }^{154}$ Dean et al reviewed the literature on the therapeutic effect of $N$-acetylcysteine in psychiatric disorders, including bipolar disorder, and found it to be beneficial in patients with bipolar depression. ${ }^{155}$ It is well tolerated by patients with bipolar disorder, although it needs to be taken for 8 weeks ( $2 \mathrm{~g}$ /day) to achieve a positive response.

\section{Hormones in mood disorders}

Dehydroepiandrosterone (DHEA) is an androgen produced by the adrenal glands, levels of which tend to decrease during mid-life in men and women. Lower levels of DHEA have been reported in patients with major depression, and use of DHEA has been associated with improved mood. An increase in DHEA sulfate, the primary metabolite of DHEA, has also been associated with improvement in depression and dysthymia. ${ }^{156-157}$ In a randomized controlled trial, 23 men and 23 women with major or minor mid-life depression were given DHEA $90 \mathrm{mg} /$ day for three weeks, then $450 \mathrm{mg} /$ day for a further three weeks, or placebo for six weeks. A $50 \%$ or greater reduction in baseline Hamilton Depression Rating scores was observed in the 23 subjects who took DHEA and in 13 subjects who took placebo. Patients taking DHEA also showed improvement in sexual function. ${ }^{158}$ DHEA has been used effectively in patients with human immunodeficiency virus/acquired immune deficiency syndrome and subsyndromal depression or chronic dysthymia. Of 145 such patients given DHEA $100-400 \mathrm{mg} /$ day for 8 weeks, 64\% showed a more than 50\% reduction in depression scores compared with $38 \%$ of those given placebo. ${ }^{159}$ The response was maintained for 8 months of follow-up, and was higher among those with increased levels of DHEA sulfate. ${ }^{159}$ Arguably, subsyndromal depression and dysthymia are not the same as major depression. In a recent study, DHEA $100 \mathrm{mg} /$ day or placebo was administered to 26 patients with anorexia nervosa, whose assessment included mood symptoms. Patients receiving DHEA experienced significant improvement in mood and body mass index, although there was no difference in bone marrow density. Thus, comorbid depression in patients with eating disorders may benefit from the use of DHEA. ${ }^{160}$ DHEA should be used in low doses in bipolar patients because it may induce manic-like symptoms, irritation, and bouts of aggression, and increase testosterone and estrogen levels, resulting in an elevated risk of uterine or breast cancer, vaginal bleeding, endometrial hyperplasia, and venous thrombosis. ${ }^{57}$ 


\section{Ayurvedic medicine in mood disorders}

Ayurvedic medicine is an ancient healing system used in India, which is now practiced worldwide. ${ }^{161}$ Ayurveda denotes longevity. The theory of Ayurveda is based on balancing the individual's three constitutional "doshas", ie, vata, pitta, and kappa, which arise from five elements of ancient philosophy, being fire, water, air, earth, and space. ${ }^{162-163}$ It is believed that health or sickness depends on the presence or absence of a balanced state. Both intrinsic and extrinsic factors, such as an indiscriminate diet, undesirable habits, not observing the rules of healthy living, seasonal abnormalities, lack of exercise, and misuse of body and mind can result in lack of balance in the body. ${ }^{164}$ Ayurvedic medicine includes several treatment options, which balance three disturbed doshas (Table 3). Diagnosis is based on a comprehensive history, detailed physical examination, measurement of vital signs including pulse, and relevant laboratory tests. ${ }^{30}$ Ashwagandha, along with combinations of herbs, such as Amrit kalash and mentat, and antidepressants can be used in depressed patients. ${ }^{30,165-168}$

There has been difficulty in conducting randomized controlled trials in Ayurvedic medicine because most treatments involve multiple herbs, changes in diet and lifestyle, and treatments are individualized and target the entire person. ${ }^{169}$ Further, the effects of Ayurvedic herbs tend to be mild and slow in onset. Most Ayurvedic herbs do tend to work gradually and with increasing efficacy as the system habituates to consistent dosing. This is often true of herbs that are prescribed for mood disorders. However, the effect of Ayurvedic herbs is not always mild. With accurate tailoring of herbal preparations, herbal therapy can be powerful in effecting change in the balance of body and mind, eg, with mood disorders that often have complex multifactorial origins. Patients who are intolerant to prescription medications fare better with Ayurvedic interventions, including panchakarma detoxification. ${ }^{162}$ Small preliminary studies of major depression treated with herbs, herbal mixtures, and Rasayanas (a special branch of Ayurveda aiming to rejuvenate and nourish the body at all levels and comprises several products manufactured from a combination of herbs) have demonstrated improvement in depression scores. ${ }^{163}$ Sharma et al recommended larger controlled studies in major depression. ${ }^{163}$ Berberine, a traditional alkaloid plant used in Ayurvedic and traditional Chinese medicine, is reported to improve depression. ${ }^{170}$ Posmontier and Teitelbaum have discussed the use of Ayurvedic medicine to treat postpartum depression. ${ }^{171}$

\section{Homeopathy in mood disorders}

Homeopathy is a traditional medical system that uses a holistic approach. Homeopathy means treating diseases with minute doses of substances which are capable of producing symptoms similar to the disease when taken by healthy people. In homeopathy, the natural law of healing is known as Similia Similibus Curantur, meaning "likes are cured by likes". ${ }^{163}$ Homeopathy is practiced in many places around the world. An audit of UK homeopathic clinics revealed that more than $84 \%$ of consultees reported improvement in mental health problems, including depression, and improvement in well-being. None of the 273 patients in that study reported deterioration, and use of conventional medicines was reduced in $25 \%$ of patients. ${ }^{172}$ Homeopathic medicines have been shown to be safe in high dilutions. ${ }^{57}$ In a systematic review of homeopathic studies in depression, Pilkington et al concluded that the different kinds of homeopathy, such as individualized prescribing, limited list prescribing, and standardized complexes used in these studies make interpretation of results more difficult. ${ }^{173}$ According to one study, ${ }^{174}$ the most commonly treated conditions in the practice of homeopathy were depression and anxiety disorders. Positive outcomes were most frequently observed in irritable bowel syndrome (73.9\%), depression (63.6\%), and anxiety (61.0\%). Which components of the treatment were most responsible for the outcomes is unclear. ${ }^{174} \mathrm{~A}$ systematic review of randomized placebo-controlled studies ( 25 eligible studies from an initial pool of 1431) of homeopathic treatments in psychiatry found beneficial effects in several mental health disorders, including functional fibromyalgia and chronic fatigue syndrome. No study of patients with major depression was found in a literature review, ${ }^{175}$ which called for randomized controlled trials using homeopathic interventions in these disorders.

\section{Mind-body-spirit approaches in mood disorders}

There are a large number of mind-body-spirit practices that have been used effectively in major depression. ${ }^{176} \mathrm{It}$ is widely accepted that most conventional antidepressant drugs increase levels of the relevant neurotransmitters, such as serotonin, norepinephrine, and dopamine, in the synapse. Mind-bodyspirit approaches are also likely to operate through the same mechanism as antidepressants, and do so in a manner similar to that of psychotherapy. Evidently, psychotherapy-induced neurotransmitter changes are similar to those caused by antidepressants. Common approaches such as yoga, meditation, exercise, and acupuncture are reviewed here. 


\section{Yoga}

Pilkington et al reported a positive impact of yoga on depression, although methodological weaknesses make the study results hard to interpret. ${ }^{177} \mathrm{~A}$ study of 71 normal adults compared visualization and relaxation techniques with 30 minutes of yoga postures and breathing exercises, and the results indicated that the participants in the yoga group became more energetic and alert with improved mood. ${ }^{178}$ Kundalini yoga techniques have also been found to be effective in depression. ${ }^{179}$ In another study, 113 psychiatric inpatients who attended Hatha yoga classes experienced a significant reduction in symptoms of depression. Improvements also occurred in anxiety, depression, hostility, fatigue, and confusion. ${ }^{180}$ Lavey et al and Weintraub suggest that yoga has a considerable benefit for patients with depression. ${ }^{180-181}$

In another study, 28 patients with mild depression who participated in two one-hour Iyengar yoga classes showed a significant reduction in depression scores compared with a control group. ${ }^{182}$ To benefit from Iyengar yoga, patients with treatment-resistant depression need long-term exposure to yoga practices. ${ }^{183}$ Other variants of yoga, such as Shavasana and Sudarshan Kirya, are also effective in mild-to-severe depression, including in older adults. ${ }^{184-186}$ Brown and Gerberg have developed a neurophysiological model of Sudarshan Kirya and discussed its clinical usefulness in depressive disorder. ${ }^{187,188}$ Other yoga researchers have found LifeForce yoga to be effective in depression. ${ }^{189}$ Sudarshan Kirya has been shown to increase serum levels of brainderived neurotrophic factor, an indicator of neuroplasticity, which is correlated with improvement in depression. ${ }^{190}$

\section{Meditation}

Meditation is a highly introspective practice that is used worldwide by people with and without health problems. Manocha et al assessed the effect of meditation on work stress, anxiety, and mood in 178 full-time workers who participated in a randomized, controlled, 8-week, three-arm trial comparing a mental silence meditation approach with an active "relaxation" control and a wait-list control. The study demonstrated a significant improvement in the meditation group compared with the relaxation control and wait-list groups. This and other research has shown that mental silence meditation, also known as Sahaga yoga, is a safe and effective strategy for dealing with work stress and depression. ${ }^{191}$ Yoga can enhance wellness ${ }^{192}$ and also significantly decreases depressive symptoms. ${ }^{193}$

Eisendrath et al reported a patient with treatmentresistant depression who was treated with mindfulness-based cognitive therapy, which is an 8-week intervention that uses mindfulness meditation. The focus of mindfulness-based cognitive therapy is on decreasing rumination, enhancing self-compassion, increasing acceptance, and decreasing avoidance. ${ }^{194}$ Reiki, a related technique, is "a meditated state in which a practitioner channels Reiki energy from a universal source to another human being". ${ }^{195,196}$ Bowden et al assessed the effect of Reiki on college students and found that it significantly reduced symptoms of depression and anxiety both immediately after treatment and 5 weeks post-treatment. ${ }^{197}$

\section{Exercise}

Regular exercise is important for maintaining good physical and mental health. Engaging in exercise for 45 minutes on five days a week is associated with improvement in patients with moderate depression. ${ }^{198}$ This effect is irrespective of age, gender, severity of depression, and type of exercise. ${ }^{199}$ The positive impact of exercise on depression is mainly attributed to an increase in serotonin, norepinephrine, and endorphins in the brain. Numerous other studies support the benefits of moderate aerobic exercise on depression in various populations..$^{33,200-202}$ Exercise has been used as an adjunct and also as augmentation therapy with pharmacotherapy/ psychotherapy in depressive symptoms, and in patients with mild-to-moderate depression and anxiety with good outcomes. ${ }^{200}$ In addition, dance therapy has been shown to decrease depression to a greater extent than either music therapy or a movement-only control. ${ }^{203}$

Biofeedback is based on the principle of using feedback from one's body as a way of learning to control and change internal processes, with the intention of improving overall health and functioning. It is relatively safe and noninvasive, but could have an adverse effect on those with pacemakers. ${ }^{204,205}$ Use of biofeedback results in a significant reduction in symptoms of mild-to-moderate depression. ${ }^{206}$

\section{Acupuncture}

Acupuncture is a traditional Chinese method used widely for treating a variety of physical and mental health problems. Kim reviewed the biological mechanisms of acupuncture and effectiveness of electroacupuncture stimulation on depression as part of Yin Tang and Bai Hui. Kim concluded that the results were inconsistent due to use of different acupuncture protocols. ${ }^{207}$ In one pilot study, 30 subjects with treatment-resistant depression were randomized to receive 30 minutes of open acupuncture on a weekly and 
twice-weekly basis. The results indicated a significant improvement of depression scores in both groups, with no significant difference between them. Therefore, acupuncture may be an effective treatment for patients with treatmentresistant depression. It is safe and well tolerated with only mild side effects, ie, bruising, pain, and bleeding at the needle site. ${ }^{208}$ Other studies also support the benefits of yoga, meditation, exercise, and acupuncture in mood disorders. ${ }^{208-211}$ Ventegodt and Merrick have suggested that nondrug CAM therapies appear to be safe, even for patients with serious physical and mental disorders. ${ }^{212}$

\section{Integrative approach}

Integrative medicine uses a holistic approach, and is recommended in the management of depression. There are many clinical trials assessing integrative therapies for depression and other mood disorders, although they are yet to be consistently used in clinical practice, despite the need..$^{57,209,213}$ Internet-based integrative psychiatric interventions have been explored as a way to meet this need. Researchers have developed an integrative, webbased program (Deprexis ${ }^{\circledR}$ ) that uses behavioral activation, cognitive restructuring, mindfulness/acceptance exercises, and social skills training. In a randomized clinical trial that included 396 subjects, researchers found a significant positive impact of this method on depression and on social functioning in those with mood disorders. ${ }^{214}$ There are now many webbased programs that help people to overcome depression and other mental health problems. ${ }^{215-218}$

\section{Discussion}

CAM is not a primary treatment for mood or other psychiatric disorders. However, level 1 evidence is beginning to emerge. There are a variety of clinical scenarios in which a clinician might recommend CAM for a mood disorder, including:

- patients who do not respond to antidepressant treatment

- development of intolerable side effects to first-line antidepressants

- a condition for which there are no effective treatments

- patients who are resistant to standard treatments and augmentation strategies

- patients on medications which are necessary but causing side effects that could be alleviated by CAM

- mitigate effects of risk factors

- those who want to explore the full range of services and options

- a situation in which there is no access to standard treatment
- when the patient is uncomfortable with modern medications

- when the patient is more comfortable with CAM therapies

- the patient cannot afford the cost of modern medication

- multiple, complex comorbid medical conditions associated with depression.

Mood disorders present in many different ways and are associated with a variety of biological, psychological, social, and environmental factors that contribute to their pathogenesis. Co-occurring psychiatric and physical conditions further complicate the treatment of mood disorders. ${ }^{8-11}$ Standard pharmacological and psychotherapies used in patients with depression have resulted in the following outcomes: $30 \%$ of patients remit, another $30 \%$ show a partial response, and the rest are resistant to treatment. ${ }^{12,13}$ Overall, 30\%-40\% of patients with major depression would benefit from CAM. ${ }^{12,13}$ Open-label clinical trials of CAM are more abundant than randomized controlled trials. The American Psychiatric Association Task Force report on CAM in major depressive disorder recommends more rigorous and larger studies in major depression. Further, each type of CAM must be evaluated separately in adequately powered controlled trials. This report also suggests that several CAM treatments presently appear promising in major depression and deserve further study. ${ }^{38}$ There are more than 120 CAM therapies used worldwide, yet their role in the treatment of mood disorders is limited because they have not all been studied scientifically.

Guidelines have been developed for using CAM in clinical practice. These emphasize the taking of a full patient history, conducting a complete physical examination, laboratory investigations, and a review of medications in order to make an accurate diagnosis and develop a treatment plan. All information gathered from the patient needs to be documented in the medical notes. ${ }^{37,39,187,188}$ Web-based CAM programs may help to meet the increasing demand for such treatments by patients with depression and mood disorders. ${ }^{214-218}$ Whether or not integrative medicine and $\mathrm{CAM}^{57,209,213}$ can shift the therapeutic paradigm from conventional treatments to traditional therapies in the management of mood disorders is debatable.

\section{Limitations}

This narrative review of the literature has some limitations. For example, limiting the literature search to papers published in the English language could have missed many relevant publications. Other relevant articles could also have been missed because not all full articles and abstracts were available. The inclusion of small open-label studies among the references that provide "evidence-based data" 
is problematic because of the risk for over-interpretation of results collected with limited scientific rigor. Lack of replication studies further limits the interpretation of individual studies. The strength of this narrative review is that it has smoothly organized widely scattered data on the therapeutic effects of CAM in mood disorders.

\section{Recommendations}

CAM therapies are expanding in number and being tested with increasing scientific rigor, similar to the clinical trials that evaluate modern drugs for depression and other mood disorders. Solid evidence is emerging about the efficacy of several types of CAM in these conditions. There is even some evidence that nutraceuticals, botanicals, and nutrients could be used alone as first-line treatments in mild-to-moderate mood disorders. However, severe depression, including psychotic depression, bipolar disorder with rapid cycling, and treatment-resistant depression require antidepressants, mood stabilizers, and atypical antipsychotics. CAM may be useful as an adjunct to conventional therapies for both acute treatment and prevention of recurrence of these disorders, perhaps with a reduction in adverse effects. Patients suffering depression comorbid with liver disease can benefit from S-adenosylmethionine, which not only improves depression but also protects the liver and restores liver function. Levodopa is a well known treatment for Parkinson's disease, and is known to deplete S-adenosylmethionine in the central nervous system, resulting in depression that can be improved by S-adenosylmethionine supplementation. Increased production of homocysteine due to genetic polymorphism of the methyltetrahydrofolate reductase gene $(\mathrm{C} / \mathrm{T}$ and $\mathrm{T} / \mathrm{T}$ instead of $\mathrm{C} / \mathrm{C}$ ) is associated with a greater risk of cardiovascular disease. Reduction in levels of both S-adenosylmethionine and folate may result in depression that responds poorly to antidepressants yet robustly to supplementation with S-adenosylmethionine and folate. ${ }^{41,42,102,103}$

Although St John's wort alleviates depression in both men and women, it is particularly useful in women who cannot tolerate antidepressants. In addition to enhancing well-being, Rhodiola rosea is recommended for the treatment of mildto-moderate depression, but needs to be used cautiously in women with a family or personal history of estrogensensitive breast cancer. Pregnant women are at higher risk for developing major depression, and all available antidepressants tend to cause adverse effects on the fetus or newborn, but omega-3 fatty acids are useful alternatives, and with no adverse effects. Further, adjunctive use of omega-3 fatty acids at 2-3 g/day with an EPA to DHA ratio of 2:1 is also recommended in bipolar disorder, given that it augments the response to antidepressants and mood stabilizers. Similarly, choline, inositol, 5-hydroxy-L-tryptophan, $\mathrm{N}$-acetylcysteine, and DHEA are all reported to be more or less effective in bipolar depression. Ayurveda and homeopathic medicine need large-scale, randomized controlled trials to establish or refute their value in the treatment of mood disorders. Mindbody-spirit therapies, especially regular and long-term yoga practices, are critical for patients with moderate to-severe depression to sustain their benefits. A number of studies also support the effectiveness of meditation, exercise, and acupuncture in major depression. Integrative medicine with an underlying philosophy that involves a holistic approach to health care uses a combination of therapies to enhance the treatment of mood disorders. Randomized controlled trials continue to be needed to provide evidence for or against the use of CAM for mood disorders in the future.

\section{Acknowledgments}

The authors acknowledge the help of staff at the National Center for Complementary and Alternative Medicine, Riyadh, in searching for relevant literature on mood disorders and CAM. We also sincerely acknowledge the help of Harold Koenig, Duke University Medical Center and King Abdulaziz University, Jeddah, Kingdom of Saudi Arabia, in revising and editing the second draft of this manuscript.

\section{Disclosure}

The authors report no conflicts of interest in this work.

\section{References}

1. Herman PM, Poindexter BL, Witt CM, Eisenberg DM. Are complementary therapies and integrative care cost-effective? A systematic review of economic evaluations. BMJ Open. 2012;2:e001046.

2. World Health Organization. World Mental Health Survey Consortium: prevalence, severity and unmet need for treatment of mental disorders in WHO world mental health surveys. JAMA. 2004;291:2581-2590.

3. Bromet E, Andrade LH, Hwang I, et al. Cross-national epidemiology of DSM-IV major depressive episode. BMC Med. 2011;9:90.

4. Kessler RC. The costs of depression. Psychiatr Clin North Am. 2012;35:1-14

5. Fandiño-Losada A, Forsell Y, Lundberg I. Demands, skill discretion, decision authority and social climate at work as determinants of major depression in a 3-year follow-up study. Int Arch Occup Environ Health July 4, 2012. [Epub ahead of print.]

6. Nordentoft M. Prevention of suicide and attempted suicide in Denmark Epidemiological studies of suicide and intervention studies in selected risk groups. Dan Med Bull. 2001;54:306-369.

7. Freeman EJ, Colpe LJ, Strine TW, et al. Public health surveillance for mental health. Prev Chronic Dis. 2010;7:A17.

8. Lauterbach E, Rumpf HJ, Ahrens B, et al. Assessing dimensional and categorical aspects of depression: validation of the AMDP Depression Scale. Eur Arch Psychiatry Clin Neurosci. 2005;255:15-19.

9. Baumeister H, Hutter N, Bengel J. Psychological and pharmacological interventions for depression in patients with coronary artery disease. Cochrane Database Syst Rev. 2011;9:CD008012.

10. National Health Service. Depression in adults with a chronic physical health problem. NICE clinical guideline 91; 2010. Available from: http:// www.nice.org.uk/guidance/CG91. Accessed March 20, 2013. 
11. Maes M, Kubera M, Obuchowiczwa E, Goehler L, Brzeszcz J. Depression's multiple comorbidities explained by neuroinflammatory and oxidative and nitrosative stress pathways. Neuro Endocrinol Lett. 2011;32:7-24.

12. Al-Harbi KS. Treatment-resistant depression: therapeutic trends, challenges, and future directions. Patient Prefer Adherence. 2012;6: 369-388.

13. Al-Harbi KS, Qureshi NA. Neuromodulation therapies and treatmentresistant depression. Med Devices (Auckl). 2012;5:53-65.

14. American Psychiatric Association. Diagnostic and Statistical Mental Disorders, Fourth Edition, Text Revision. Washington, DC: American Psychiatric Association; 1994.

15. World Health Organization. International Classification of Diseases-10. Geneva, Switzerland: World Health Organization; 1990

16. Walpole SC, McMillan D, House A, Cottrell D, Mir G. Interventions for treating depression in Muslim patients: a systematic review. JAffect Disord. 2013;145:11-20.

17. Bartolomucci A, Leopardi R. Stress and depression: preclinical research and clinical implications. PLoS One. 2009;4:e4265.

18. Fava M, Farabaugh AH, Sickinger AH, et al. Personality disorders and depression. Psychol Med. 2002;32:1049-1057.

19. Ito $\mathrm{N}$, Hori $\mathrm{A}$, Yabe $\mathrm{T}$, et al. Involvement of neuropeptide y signaling in the antidepressant-like effect and hippocampal cell proliferation induced by kososan, a kampo medicine, in the stress-induced depression-like model mice. Biol Pharm Bull. 2012;35:1775-1783.

20. Wolkowitz OM, Reus VI, Mellon SH. Of sound mind and body: depression, disease, and accelerated aging. Dialogues Clin Neurosci. 2011;13:25-39.

21. Dacher E. The development of an integrated medical model: toward a postmodern medicine. In: Micozzi MS, editor. Fundamentals of Complementary and Alternative Medicine. New York, NY: Churchill Livingstone; 2001.

22. Sarris J. Clinical depression: an evidence-based integrative complementary medicine treatment model. Altern Ther Health Med. 2011;17:26-37.

23. Pampallona S, Bollini P, Tibaldi G, Kupelnick B, Munizza C. Combined pharmacotherapy and psychological treatment for depression: a systematic review. Arch Gen Psychiatry. 2004;61:714-719.

24. Thase ME. Evaluating antidepressant therapies: remission as the optimal outcome. J Clin Psychiatry. 2003;64 Suppl 13:18-25.

25. Baghai TC, Moller HJ, Rupprecht R. Recent progress in pharmacological and non-pharmacological treatment options of major depression. Curr Pharm Des. 2006;12:503-515.

26. Trivedi MH, Rush AJ, Wisniewski SR, et al. Evaluation of outcomes with citalopram for depression using measurement-based care in STAR*D: implications for clinical practice. Am J Psychiatry. 2006;163:28-40.

27. Bambauer KZ, Adams AS, Zhang F, et al. Physician alerts to increase antidepressant adherence: fact or fiction? Arch Intern Med. 2006;166: 498-504.

28. Fava M. Pharmacological approaches to the treatment of residual symptoms. J Psychopharmacol. 2006;20 Suppl 3:29-34.

29. Petersen TJ. Enhancing the efficacy of antidepressants with psychotherapy. J Psychopharmacol. 2006;20 Suppl 3:19-28.

30. Department of Ayush, Ministry of Health and Family Welfare. Available from: http://indianmedicine.nic.in/. Accessed October 10, 2012.

31. Perron BE, Jarman CN, Kilbourne AM. Access to conventional mental health and medical care among users of complementary and alternative medicine with bipolar disorder. J Nerv Ment Dis. 2009;197:287-290.

32. Jarman CN, Perron BE, Kilbourne AM, Teh CF. Perceived treatment effectiveness, medication compliance, and complementary and alternative medicine use among veterans with bipolar disorder. J Altern Complement Med. 2010;16:251-255.

33. Nahas R, Sheikh O. Complementary and alternative medicine for the treatment of major depressive disorder. Can Fam Physician. 2011;57: 659-663.

34. Muskin PR. Introduction: herbs and hermeneutics. In: Complementary and Alternative Medicine and Psychiatry. Arlington, VA: American Psychiatric Press Inc; 2005.
35. LaPatra J. Healing: The Coming Revolution in Holistic Medicine. New York, NY: McGraw-Hill; 1978.

36. Al-Bedah A. Public perspective: information and insights in complementary and alternative medicine. Oman Med J. 2012;27:20.

37. Ravindran AV, Lam RW, Filteau MJ, et al. Canadian Network for Mood and Anxiety Treatments (CANMAT) Canadian Network for Mood and Anxiety Treatments (CANMAT). Clinical guidelines for the management of major depressive disorder in adults. V. Complementary and alternative medicine treatments. $J$ Affect Disord. 2009;117 Suppl 1:S54-S64.

38. Freeman MP, Fava M, Lake J, Trivedi MH, Wisner KL, Mischoulon D. Complementary and alternative medicine in major depressive disorder: the American Psychiatric Association Task Force report. J Clin Psychiatry. 2010;71:669-681.

39. Hoenders HJ, Appelo MT, van den Brink EH, Hartogs BMA, de Jong JTVM. The Dutch Complementary and Alternative Medicine (CAM) protocol: to ensure safe and effective use of CAM within Dutch mental health care. J Complement Altern Med. 2011;17:1197-1201.

40. Gupta S, Chauhan D, Mehla K, Sood P, Nair A. An overview of nutraceuticals: current scenario. J Basic Clin Pharm. 2010;1:55-62.

41. Bottiglieri T. S-Adenosyl-L-methionine (SAMe) from the bench to the bedside- molecular basis of pleiotrophic molecule. Am J Clin Nutr. 2002;76:1151S-1157S.

42. Brown RP, Gerbarg PL, Bottiglieri T. S-Adenosylmethionine (SAMe) for depression: biochemical and clinical evidence. Psychiatr Ann. 2002;32:29-44.

43. Carpenter DJ. St John's wort and S-adenosyl methionine as "natural" alternatives to conventional antidepressants in the era of the suicidality boxed warning: what is the evidence for clinically relevant benefit? Altern Med Rev. 2011;16:17-39.

44. Papakostas GI, Cassiello CF, Iovieno N. Folates and s-adenosylmethionine for major depressive disorder. Can J Psychiatry. 2012;57:406-413.

45. Freeman MP, Mischoulon D, Tedeschini E, et al. Complementary and alternative medicine for major depressive disorder: a meta-analysis of patient characteristics, placebo-response rates, and treatment outcomes relative to standard antidepressants. J Clin Psychiatry. 2010;71: 682-688.

46. Alpert JE, Papakostas G, Mischoulan D, et al. S-adenosyl-L-methionine (SAMe) as an adjunct for resistant major depressive disorder: an open trial following partial or nonresponse to selective serotonin reuptake inhibitors or venlafaxine. J Clin Psychopharmacol. 2004;24: 661-664.

47. Papakostas GI, Mischoulon D, Shyu I, Alpert JE, Fava M. S-adenosyl methionine (SAMe) augmentation of serotonin reuptake inhibitors for antidepressant nonresponders with major depressive disorder: a double-blind, randomized clinical trial. Am J Psychiatry. 2010;167: 942-948.

48. Ernst E. Complementary medicine. Curr Opin Rheumatol. 2003;15: $151-155$.

49. Grassetto M, Varratto A. Primary fibromyalgia is responsive to S-adenosyl-L-methionine. Curr Ther Res. 1994;55:797-806.

50. Lieber CS. S-adenosyl-L-methionine: its role in the treatment of liver diseases. Am J Clin Nutr. 2002;76:S1183-S1187.

51. Aleynik SI, Lieber CS. Polienylphosphatidylcholine corrects the alcoholinduced hepatic oxidative stress by restoring s-adenosylmethionine. Alcohol Alcohol. 2003;38:208-212.

52. Di Rocco A, Rogers JD, Brown R, Werner P, Bottiglieri T. S-adenosylL-methionine improves depression in patients with Parkinson's disease in an open label clinical trial. Mov Disord. 2000;15:1225-1229.

53. Shippy RA, Mendez D, Jones K, Cergnul I, Karpiak SE. S-adenosylL-methionine (SAMe) for the treatment of depression in people living with HIV/AIDS. BMC Psychiatry. 2004;4:38.

54. Cerutti R, Sichel MP, Perin M, et al. Psychological distress during puerperium: a novel therapeutic approach using S-adenosylmethionine. Curr Ther Res. 1993;53:707-716.

55. Surtees R, Hyland K. A method for the measurement of $\mathrm{S}$-adenosylmethionine in small volume samples of cerebrospinal fluid or brain using high-performance liquid chromatography-electro chemistry. Ann Biochem. 1989;181:333-335. 
56. Levkovitz Y, Alpert JE, Brintz CE, Mischoulon D, Papakostas GI. Effects of S-adenosylmethionine augmentation of serotonin-reuptake inhibitor antidepressants on cognitive symptoms of major depressive disorder. J Affect Disord. 2012;3:1174-1178.

57. Brown RP, Gerberg PL, Muskin PR, editors. Mood disorders. In: How to Use Herbs, Nutrients and Yoga in Mental Health. New York, NY: WW Norton \& Company; 2009.

58. El-Alfy AT, Abourashed EA, Matsumoto RR. Nature against depression. Curr Med Chem. 2012;19:2229-2241.

59. Iovieno N, Dalton ED, Fava M, Mischoulon D. Second-tier natural antidepressants: review and critique. J Affect Disord. 2011;130: 343-357.

60. Linde K, Ramirez G, Mulrow CD, Pauls A, Wesdenhammer W, Melchart D. St John's Wort for depression - an overview and metaanalysis of randomized clinical trials. BMJ. 1996;313:253-258.

61. Vorbach EU, Arnoldt KH, Hübner WD. Efficacy and tolerability of St John's wort extract LI 160 versus imipramine in patients with severe depressive episodes according to ICD-10. Pharmacopsychiatry. 1997;30 Suppl 2:81-85.

62. Schrader E. Equivalence of St John's wort extract (Ze 117) and fluoxetine: a randomized, controlled study in mild-moderate depression. Int Clin Psychopharmacol. 2000;15:61-68.

63. Shelton RC, Keller MB, Gelenberg A, et al. Effectiveness of St John's wort in major depression: a randomized controlled trial. JAMA. 2001;285:1978-1986.

64. Gelenberg AJ, Shelton RC, Crits-Christoph P, et al. The effectiveness of St John's wort in major depressive disorder: a naturalistic phase 2 follow-up in which nonresponders were provided alternate medication. J Clin Psychiatry. 2004;65:1114-1119.

65. [No authors listed]. Hypericum Depression Trial Study Group. Effect of Hypericum perforatum (St John's wort) in major depressive disorder: a randomized controlled trial. JAMA. 2002;287:1807-1814.

66. Bjerkenstedt L, Edman GV, Alken RG, Mannel M. Hypericum extract LI 160 and fluoxetine in mild to moderate depression: a randomized, placebo-controlled multi-center study in outpatients. Eur Arch Psychiatry Clin Neurosci. 2005;255:40-47.

67. Moreno RA, Teng CT, Almeida KM, Tavares Junior H. Hypericum perforatum versus fluoxetine in the treatment of mild to moderate depression: a randomized double-blind trial in a Brazilian sample. Rev Bras Psiquiatr. 2006;28:29-32.

68. Fava M, Alpert J, Nierenberg AA, et al. A double-blind, randomized trial of St John's wort, fluoxetine, and placebo in major depressive disorder. J Clin Psychopharmacol. 2005;25:441-447.

69. Chen JA, Papakostas GI, Youn SJ, et al. Association between patient beliefs regarding assigned treatment and clinical response: reanalysis of data from the Hypericum Depression Trial Study Group. J Clin Psychiatry. 2011;72:1669-1676.

70. Kasper S, Anghelescu IG, Szegedi A, Dienel A, Kieser M. Superior efficacy of St John's wort extract WS 5570 compared to placebo in patients with major depression: a randomized, double-blind, placebo-controlled, multi-center trial [ISRCTN77277298]. BMC Med. 2006;4:14.

71. Gastpar M, Singer A, Zeller K. Efficacy and tolerability of hypericum extract STW3 in long-term treatment with a once-daily dosage in comparison with sertraline. Pharmacopsychiatry. 2005;38:78-86.

72. Szegedi A, Kohnen R, Dienel A, Kieser M. Acute treatment of moderate to severe depression with hypericum extract WS 5570 (St John's wort): randomised controlled double blind non-inferiority trial versus paroxetine. BMJ. 2005;330:503.

73. Wheatley D. Hypericum in seasonal affective disorder (SAD). Curr Med Res Opin. 1999;15:33-37.

74. Singer A, Schmidt M, Hauke W, Stade K. Duration of response after treatment of mild to moderate depression with Hypericum extract STW 3-VI, citalopram and placebo: a reanalysis of data from a controlled clinical trial. Phytomedicine. 2011;18:739-742.

75. Rapaport MH, Nierenberg AA, Howland R, Dording C, Schettler PJ, Mischoulon D. The treatment of minor depression with St John's Wort or citalopram: failure to show benefit over placebo. J Psychiatr Res. 2011;45:931-941.
76. Geller SE, Studee L. Botanical and dietary supplements for mood and anxiety in menopausal women. Menopause. 2007;14(3 Pt 1): 541-549.

77. Borrelli F, Izzo AA. Herb-drug interactions with St John's wort (Hypericum perforatum): an update on clinical observations. AAPS J. 2009;11:710-727.

78. Kasper S, Gastpar M, Möller HJ, et al. Better tolerability of St John's wort extract WS 5570 compared to treatment with SSRIs: a reanalysis of data from controlled clinical trials in acute major depression. Int Clin Psychopharmacol. 2010;25:204-213.

79. Knüppel L, Linde K. Adverse effects of St John's wort: a systematic review. J Clin Psychiatry. 2004;65:1470-1479.

80. Thakor V, Leach MJ, Gillham D, Esterman A. The quality of information on websites selling St John's wort. Complement Ther Med. 2011;19:155-160.

81. Clauson KA, Santamarina ML, Rutledge JC. Clinically relevant safety issues associated with St John's wort product labels. BMC Complement Altern Med. 2008;8:42.

82. McCrea CE, Pritchard ME. Concurrent herb-prescription medication use and health care provider disclosure among university students. Complement Ther Med. 2011;19:32-36.

83. Edwards D, Heufelder A, Zimmermann A. Therapeutic effects and safety of Rhodiola rosea extract WS ${ }^{\circledR} 1375$ in subjects with life-stress symptoms results of an open-label study. Phytother Res. 2012;26:1220-1225.

84. Panossian A, Wikman G, Sarris J. Rosenroot (Rhodiola rosea): traditional use, chemical composition, pharmacology and clinical efficacy. Phytomedicine. 2010;17:481-493.

85. Darbinyan V, Aslanyan G, Amroyan E, Gabrielyan E, Malmström C, Panossian A. Clinical trial of Rhodiola rosea L. extract SHR-5 in the treatment of mild to moderate depression. Nord J Psychiatry. 2007;61: 343-348.

86. Chan SW. Panax ginseng, Rhodiola rosea and Schisandra chinensis. Int J Food Sci Nutr. 2012;63 Suppl 1:75-81.

87. Kelly GS. Rhodiola rosea: a possible plant adaptogen. Altern Med Rev. 2001;6:293-302.

88. van Diermen D, Marston A, Bravo J, Reist M, Carrupt PA, Hostettmann K. Monoamine oxidase inhibition by Rhodiola rosea L. roots. J Ethnopharmacol. 2009;122:397-401.

89. Dwyer AV, Whitten DL, Hawrelak JA. Herbal medicines, other than St John's wort, in the treatment of depression: a systematic review. Altern Med Rev. 2011;16:40-49.

90. Sarris J, Panossian A, Schweitzer I, Stough C, Scholey A. Herbal medicine for depression, anxiety and insomnia: a review of psychopharmacology and clinical evidence. Eur Neuropsychopharmacol. 2011;21:841-860.

91. Li LT, Wang SH, Ge HY, Chen J, Yue SW, Yu M. The beneficial effects of the herbal medicine Free and Easy Wanderer Plus (FEWP) and fluoxetine on post-stroke depression. J Altern Complement Med. 2008;14:841-846.

92. Rai V, Kattar P, Khatoon S, Rawat AKS, Mehrotra S. Heavy metal accumulation in some herbal drugs. Pharm Biol. 2001;39:384-387.

93. Hugget DB, Kahn IA, Allgood JC, Block DS, Schlenk D. Organochlorine pesticides and metals in select botanical dietary supplements. Bull Environ Contam Toxicol. 2001;66:150-155.

94. Ernst E, Coon JT. Heavy metals in traditional Chinese medicine: a systematic review. Clin Pharmacol Ther. 2001;70:497-504.

95. Rai V, Kakkar P, Singh J, Misra C, Kumar S, Mehrotra S. Toxic metals and organochlorine pesticides residue in single herbal drugs used in important Ayurvedic formulation- 'Dashmoola'. Environ Monit Assess. 2008;143:273-277.

96. Gasser U, Klier B, Kühn AV, Steinhoff B. Current findings on the heavy metal content in herbal drugs. Pharmeur Sci Notes. 2009;1: 37-50.

97. Sullivan J, Greenfield J, Cumberford G, Grant J, Stewart J. Extraction efficiencies of heavy metals in hydroethanolic solvent from herbs of commerce. J AOAC Int. 2010;93:496-498.

98. Rosecrans R, Dohnal JC. The effect of complimentary and alternative medicine products on laboratory testing. Semin Diagn Pathol. 2009;26:38-48. 
99. Sadovsky R, Collins N, Tighe AP, Brunton SA, Safeer R. Patient use of dietary supplements: a clinician's perspective. Curr Med Res Opin. 2008;24:1209-1216.

100. Posadzki P, Watson L, Ernst E. Contamination and adulteration of herbal medicinal products (HMPs): an overview of systematic reviews. Eur J Clin Pharmacol. 2013;69:295-307.

101. Ellsworth-BowersER,CorwinEJ.Nutritionand thepsychoneuroimmunology of postpartum depression. Nutr Res Rev. 2012;25:180-192.

102. Bottiglieri T. Folate, vitamin B12, and neuropsychiatric disorders. Nutr Rev. 1996;54:382-390.

103. Crellin R, Bottiglieri T, Reynolds EH. Folates and psychiatric disorders. Clinical potential. Drugs. 1993;45:623-636.

104. Procter A. Enhancement of recovery from psychiatric illness by methylfolate. Br J Psychiatry. 1991;159:271-272.

105. Bell IR, Edman JS, Morrow FD, et al. Brief communication. Vitamin B1, B2, and B6 augmentation of tricyclic antidepressant treatment in geriatric depression with cognitive dysfunction. $J \mathrm{Am}$ Coll Nutr. 1992;11:159-163.

106. Coppen A, Bailey J. Enhancement of the antidepressant action of fluoxetine by folic acid: a randomised, placebo controlled trial. J Affect Disord. 2000;60:121-130.

107. Christensen H, Aiken A, Batterham PJ, et al. No clear potentiation of antidepressant medication effects by folic acid + vitamin B12 in a large community sample. J Affect Disord. 2011;130:37-45.

108. Walker JG, Mackinnon AJ, Batterham P, et al. Mental health literacy, folic acid and vitamin B12, and physical activity for the prevention of depression in older adults: randomised controlled trial. Br J Psychiatry. 2010;197:45-54.

109. Lange H, Suryapranata H, De Luca G, et al. Folate therapy and in-stent restenosis after coronary stenting. $N$ Engl J Med. 2004;350: 2673-2681.

110. Haines ST, Park SK. Vitamin D supplementation: what's known, what to do, and what's needed. Pharmacotherapy. 2012;32:354-382.

111. Dumville JC, Miles JN, Porthouse J, Cockayne S, Sexon L, King C. Can vitamin D supplementation prevent winter-time blues? A randomized trial among older women. J Nutr Health Aging. 2006;10:151-153.

112. Jorde R, Sneve M, Figenschau Y, Svartberg J, Waterloo K. Effects of vitamin D supplementation on symptoms of depression in overweight and obese subjects: randomized double blind trial. J Intern Med. 2008;264:599-609.

113. Kjærgaard M, Waterloo K, Wang CE, et al. Effect of vitamin D supplement on depression scores in people with low levels of serum 25-hydroxyvitamin D: nested case-control study and randomised clinical trial. Br J Psychiatry. 2012;201:360-368.

114. Bertone-Johnson ER, Powers SI, Spangler L, et al. Vitamin D supplementation and depression in the women's health initiative calcium and vitamin D trial. Am J Epidemiol. 2012;176:1-13.

115. Tariq MM, Streeten EA, Smith HA, et al. Vitamin D: a potential role in reducing suicide risk? Int J Adolesc Med Health. 2011;23: 157-165.

116. Hirashima F, Parow AM, Stoll AL, et al. Omega-3 fatty acid treatment and T(2) whole brain relaxation times in bipolar disorder. Am J Psychiatry. 2004;161:1922-1924.

117. ParkerG, Gibson NA, BrotchieH,Heruc G, ReesAM,Hadzi-Pavlovic D. Omega-3 fatty acids and mood disorders. Am J Psychiatry. 2006; 163:969-978.

118. Rocha Araujo DM, Vilarim MM, Nardi AE. What is the effectiveness of the use of polyunsaturated fatty acid omega-3 in the treatment of depression? Expert Rev Neurother. 2010;10:1117-1129.

119. Sublette ME, Ellis SP, Geant AL, Mann JJ. Meta-analysis of the effects of eicosapentaenoic acid (EPA) in clinical trials in depression. J Clin Psychiatry. 2011;72:1577-1584.

120. Gertsik L, Poland RE, Bresee C, Rapaport MH. Omega-3 fatty acid augmentation of citalopram treatment for patients with major depressive disorder. J Clin Psychopharmacol. 2012;32:61-64.

121. Sublette ME, Hibbeln JR, Galfalvy H, Oquendo MA, Mann JJ. Omega-3 polyunsaturated essential fatty acid status as a predictor of future suicide risk. Am J Psychiatry. 2006;163:1100-1102.
122. McNamara RK, Hahn CG, Jandacek R, et al. Selective deficits in the omega-3 fatty acid docosahexaenoic acid in the postmortem orbitofrontal cortex of patients with major depressive disorder. Biol Psychiatry. 2007;62:17-24.

123. Freeman MP, Hibbeln JR, Wisner KL, et al. Omega-3 fatty acids: evidence basis for treatment and future research in psychiatry. $J$ Clin Psychiatry. 2006;67:1954-1967.

124. Su KP, Huang SY, Chiu CC, Shen WW. Omega-3 fatty acids in major depressive disorder. A preliminary double-blind, placebo-controlled trial. Eur Neuropsychopharmacol. 2003;13:267-271.

125. Nemets B, Stahl Z, Belmaker RH. Addition of omega-3 fatty acid to maintenance medication treatment for recurrent unipolar depressive disorder. Am J Psychiatry. 2002;159:477-479.

126. Timonen M, Horrobin D, Jokelainen J, Laitinen J, Herva A, Räsänen P. Fish consumption and depression: the Northern Finland 1966 birth cohort study. J Affect Disord. 2004;82:447-452.

127. Murphy BL, Stoll AL, Harris PQ, et al. Omega-3 fatty acid treatment, with or without cytidine, fails to show therapeutic properties in bipolar disorder: a double-blind, randomized add-on clinical trial. J Clin Psychopharmacol. 2012;32:699-703.

128. McNamara RK. Evaluation of docosahexaenoic acid deficiency as a preventable risk factor for recurrent affective disorders: current status, future directions, and dietary recommendations. Prostaglandins Leukot Essent Fatty Acids. 2009;81:223-231.

129. Noaghiul S, Hibbeln JR. Cross-national comparisons of seafood consumption and rates of bipolar disorders. Am J Psychiatry. 2003;160: 2222-2227.

130. Osher Y, Bersudsky Y, Belmaker RH. Omega-3 eicosapentaenoic acid in bipolar depression: report of a small open-label study. J Clin Psychiatry. 2005;66:726-729.

131. Frangou S, Lewis M, McCrone P. Efficacy of ethyl-eicosapentaenoic acid in bipolar depression: randomised double-blind placebo-controlled study. Br J Psychiatry. 2006;188:46-50.

132. Keck PE Jr, Mintz J, McElroy SL, et al. Double-blind, randomized, placebo-controlled trials of ethyl-eicosapentanoate in the treatment of bipolar depression and rapid cycling bipolar disorder. Biol Psychiatry. 2006;60:1020-1022.

133. Osher Y, Belmaker RH. Omega-3 fatty acids in depression: a review of three studies. CNS Neurosci Ther. 2009;15:128-133.

134. Sarris J, Mischoulon D, Schweitzer I. Omega-3 for bipolar disorder: meta-analyses of use in mania and bipolar depression. $J$ Clin Psychiatry. 2012;73:81-86.

135. Hibbeln JR. Seafood consumption, the DHA content of mothers' milk and prevalence rates of postpartum depression: a cross-national, ecological analysis. J Affect Disord. 2002;69:15-29.

136. Su KP, Huang SY, Chiu TH, et al. Omega-3 fatty acids for major depressive disorder during pregnancy: results from a randomized, double-blind, placebo-controlled trial. J Clin Psychiatry. 2008;69: 644-651.

137. Freeman MP, Hibbeln JR, Wisner KL, Brumbach BH, Watchman M, Gelenberg AJ. Randomized dose-ranging pilot trial of omega-3 fatty acids for postpartum depression. Acta Psychiatr Scand. 2006;113:31-35.

138. Deligiannidis KM, Freeman MP. Complementary and alternative medicine for the treatment of depressive disorders in women. Psychiatr Clin North Am. 2010;33:441-463.

139. Lustyk MKB, Gerrish WG. Premenstrual syndrome and premenstrual dysphoric disorder: issues of quality of life, stress and exercise. In: Preedy V, Watson RR, editors. Handbook of Disease Burdens and Quality of Life Measures. Heidelberg, Germany: Springer Science + Business Media LLC; 2010.

140. Wozniak J, Biederman J, Mick E, et al. Omega-3 fatty acid monotherapy for pediatric bipolar disorder: a prospective open-label trial. Eur Neuropsychopharmacol. 2007;17:440-447.

141. Loo M, editor. Integrative Medicine for Children. St Louis, MO: Saunders Elsevier Inc; 2009.

142. Bogarapu S, Bishop JR, Krueger CD, Pavuluri MN. Complementary medicines in pediatric bipolar disorder. Minerva Pediatr. 2008;60: 103-114. 
143. Frazier EA, Fristad MA, Arnold LE. Feasibility of a nutritional supplement as treatment for pediatric bipolar spectrum disorders. J Altern Complement Med. 2012;18:678-685.

144. Stoll AL, Sachs GS, Cohen BM, Lafer B, Christensen JD, Renshaw PF. Choline in the treatment of rapid-cycling bipolar disorder: clinical and neurochemical findings in lithium-treated patients. Biol Psychiatry. 1996;40:382-388.

145. Lyoo IK, Demopulos CM, Hirashima F, Ahn KH, Renshaw PF. Oral choline decreases brain purine levels in lithium-treated subjects with rapid-cycling bipolar disorder: a double-blind trial using proton and lithium magnetic resonance spectroscopy. Bipolar Disord. 2003;5: 300-306.

146. Benjamin J,Agam G,Levine J, BersudskyY, Kofman O, BelmakerRH. Inositol treatment in psychiatry. Psychopharmacol Bull. 1995;31:167-175.

147. Sarris J, Kavanagh DJ, Byrne G. Adjuvant use of nutritional and herbal medicines with antidepressants, mood stabilizers and benzodiazepines. J Psychiatr Res. 2010;44:32-41.

148. Chengappa KN, Levine J, Gershon S, et al. Inositol as an add-on treatment for bipolar depression. Bipolar Disord. 2000;2: 47-55.

149. Nierenberg AA, Ostacher MJ, Calabrese JR, et al. Treatment-resistant bipolar depression: a STEP-BD equipoise randomized effectiveness trial of antidepressant augmentation with lamotrigine, inositol, or risperidone. Am J Psychiatry. 2006;163:210-216.

150. Back EE, Henning KJ, Kallenbach LR, Brix KA, Gunn RA, Melius JM. Risk factors for developing eosinophilia myalgia syndrome (EMS) among L-tryptophan users in New York. J Rheumatol. 1993;20: 666-672.

151. Das YT, Bagchi M, Bagchi D, Preuss HG. Safety of 5-hydroxy-Ltryptophan. Toxicol Lett. 2004;150:111-122.

152. Gijsman HJ, van Gerven JM, de Kam ML, et al. Placebo-controlled comparison of three dose-regimens of 5-hydroxytryptophan challenge test in healthy volunteers. J Clin Psychopharmacol. 2002;22:183-189.

153. Smaga I, Pomierny B, Krzyżanowska W, et al. N-acetylcysteine possesses antidepressant-like activity through reduction of oxidative stress: behavioral and biochemical analyses in rats. Prog Neuropsychopharmacol Biol Psychiatry. 2012;39:280-287.

154. Sarris J, Mischoulon D, Schweitzer I. Adjunctive nutraceuticals with standard pharmacotherapies in bipolar disorder: a systematic review of clinical trials. Bipolar Disord. 2011;13:454-465.

155. Dean O, Giorlando F, Berk M. N-acetylcysteine in psychiatry: current therapeutic evidence and potential mechanisms of action. J Psychiatry Neurosci. 2011;36:78-86.

156. Bloch M, Schmidt PJ, Danaceau MA, Adams LF, Rubinow DR. Dehydroepiandrosterone treatment of midlife dysthymia. Biol Psychiatry. 1999;45:1533-1541.

157. Wolkowitz OM, Reus VI, Keebler A, et al. Double-blind treatment of major depression with dehydroepiandrosterone. Am J Psychiatry. 1999; 156:646-649.

158. Schmidt PJ, Daly RC, Bloch M, et al. Dehydroepiandrosterone monotherapy in midlife-onset major and minor depression. Arch Gen Psychiatry. 2005;62:154-162.

159. Rabkin JG, McElhiney MC, Rabkin R, McGrath PJ, Ferrando SJ. Placebo-controlled trial of dehydroepiandrosterone (DHEA) for treatment of nonmajor depression in patients with HIV/AIDS. Am J Psychiatry. 2006;163:59-66.

160. Bloch M, Ish-Shalom S, Greenman Y, Klein E, Latzer Y. Dehydroepiandrosterone treatment effects on weight, bone density, bone metabolism and mood in women suffering from anorexia nervosa-a pilot study. Psychiatry Res. 2012;200:544-549.

161. Satow YE, Kumar PD, Burke A, Inciardi JF. Exploring the prevalence of Ayurveda use among Asian Indians. J Altern Complement Med 2008;14:1249-1253.

162. Prathikanti S. Ayurvedic treatments. In: Lake J, Spiegel D, editors. Complementary and Alternative Treatments. Washington, DC: American Psychiatric Publishing; 2007.

163. Sharma H, Chandola HM, Singh G, Basisht G. Utilization of Ayurveda in health care: an approach for prevention, health promotion, and treatment of disease. Part 2-Ayurveda in primary health care. JAltern Complement Med. 2007;13:1135-1150.
164. Ven Murthy MR, Ranjekar PK, Ramassamy C, Deshpande M. Scientific basis for the use of Indian ayurvedic medicinal plants in the treatment of neurodegenerative disorders: Ashwagandha. Cent Nerv Syst Agents Med Chem. 2010;10:238-246.

165. Shrestha BG, Takagi Y, Ishii T, Wadhwa R, Kaul SC. Selective killing of cancer cells by leaf extract of Ashwagandha: identification of a tumor-inhibitory factor and the first molecular insights to its effect. Clin Cancer Res. 2007;13:2298-2306.

166. Maity T, Adhikari A, Bhattacharya K, Biswas S, Debnath PK, Maharana CS. A study on evaluation of antidepressant effect of imipramine adjunct with Aswagandha and Bramhi. Nepal Med Coll J. 2011;13:250-253.

167. Bhattacharya SK, Bhattacharya A, Sairam K, Ghosal S. Anxiolyticantidepressant activity of Withania somnifera glycowithanolides: an experimental study. Phytomedicine. 2000;7:463-469.

168. [No authors listed]. Monograph. Withania somnifera. Altern Med Rev. 2004;9:211-214.

169. Rioux J. A complex, nonlinear dynamic systems perspective on Ayurveda and Ayurvedic research. J Altern Complement Med. 2012;18:709-718.

170. Vuddanda PR, Chakraborty S, Singh S. Berberine: a potential phytochemical with multispectrum therapeutic activities. Expert Opin Investig Drugs. 2010;19:1297-1307.

171. Posmontier B, Teitelbaum M. An Ayurvedic approach to postpartum depression. Holist Nurs Pract. 2009;23:201-214.

172. Bawden S. Running an NHS community homeopathy clinic - 10-year anniversary 2001-2011. Homeopathy. 2012;101:51-56.

173. Pilkington K, Kirkwood G, Rampes H, Fisher P, Richardson J. Homeopathy for depression: a systematic review of the research evidence. Homeopathy. 2005;94:153-163.

174. Mathie RT, Robinson TW. Outcomes from homeopathic prescribing in medical practice: a prospective, research-targeted, pilot study. Homeopathy. 2006;95:199-205.

175. Davidson JR, Crawford C, Ives JA, Jonas WB. Homeopathic treatments in psychiatry: a systematic review of randomized placebo-controlled studies. J Clin Psychiatry. 2011;72:795-805.

176. Selhub E. Mind-body medicine for treating depression: using the mind to alter the body's response to stress. Alternative and Complementary Therapies. 2007;13:4-9.

177. Pilkington K, Kirkwood G, Rampes H, Richardson J. Yoga for depression: the research evidence. J Affect Disord. 2005;89:13-24.

178. Wood C. Mood change and perceptions of vitality: a comparison of the effects of relaxation, visualization and yoga. $J R S o c$ Med. 1993;86:254-258.

179. Shannahoff-Khalsa DS. Kundalini yoga meditation techniques for the treatment of obsessive-compulsive and OC spectrum disorders. Brief Treat Crisis Interv. 2003;3:369-382.

180. Lavey R, Sherman T, Mueser KT, Osborne DD, Currier M, Wolfe R. The effects of yoga on mood in psychiatric inpatients. Psychiatr Rehabil J. 2005;28:399-402.

181. Weintraub A. Yoga for Depression: A Compassionate Guide to Relieve Suffering Through Yoga. New York, NY: Three Rivers Press; 2004.

182. Woolery A, Myers H, Sternlieb B, Zeltzer L. A yoga intervention for young adults with elevated symptoms of depression. Altern Ther Health Med. 2004;10:60-63.

183. Shapiro D, Cook IA, Davydov DM, Ottaviani C, Leuchter AF, Abrams M. Yoga as a complementary treatment of depression: effects of traits and moods on treatment outcome. Evid Based Complement Alternat Med. 2007;4:493-502.

184. Khumar SS, Kaur PKS. Effectiveness of Shavasana on depression in university students. Indian J Clin Psychol. 1993;20:82-87.

185. Tsang HW, Fung KM, Chan AS, Lee G, Chan F. Effect of a qigong exercise programme on elderly with depression. Int $J$ Geriatr Psychiatry. 2006;21:890-897.

186. Janakiramaiah N, Gangadhar BN, NagaVenkatesha Murthy PJ, Harish MG, Subbakrishna DK, Vedamurthachar A. Antidepressant efficacy of Sudarshan Kriya Yoga (SKY) in melancholia: a randomized comparison with electroconvulsive therapy (ECT) and imipramine. J Affect Disord. 2000;57:255-259. 
187. Brown RP, Gerberg PL. Sudarshan Kirya Yogic breathing in the treatment of stress, anxiety and depression: Part 1 Neurophysiologic model. J Altern Complement Med. 2005;11:189-201.

188. Brown RP, Gerberg PL. Sudarshan Kirya Yogic breathing in the treatment of stress, anxiety and depression: Part I1 Clinical applications and guidelines. J Altern Complement Med. 2005;11:711-717.

189. Bennett SM, Weintraub A, Khalsa SS. Initial evaluation of the LifeForce yoga program as a therapeutic intervention for depression. Int J Yoga Therap. 2008;18:49-57.

190. Pan NL, Jiang MJ, Poon PWF, Huang AM. The role of brain-derived neurotrophic factor in the antidepressant effects of Sudarshan Kriya Yoga. Master's thesis. 2006. Available from: http://ethesys.lib.ncku. edu.tw/ETD-db/ETD-search/view_etd?URN=etd-0808107-104238. Accessed October 18, 2012.

191. Manocha R, Black D, Sarris J, Stough C. A randomized, controlled trial of meditation for work stress, anxiety and depressed mood in full-time workers. Evid Based Complement Alternat Med. 2011; 2011:960583.

192. Kjellgren A, Bood SA, Axelsson K, Norlander T, Saatcioglu F. Wellness through a comprehensive Yogic breathing program - controlled pilot trial. BMC Complement Altern Med. 2007;7:43.

193. Mehta P, Sharma M. Yoga as a complementary therapy for clinical depression. Complement Health Pract Rev. 2010;15:156-170.

194. Eisendrath S, Chartier M, McLane M. Adapting mindfulness-based cognitive therapy for treatment-resistant depression. Cogn Behav Pract. 2011;18:362-370.

195. Plodek J. Reiki: an ancient therapy in modern times. In: Freeman L, editor. Mosby's Complementary and Alternative Medicine: A ResearchBased Approach, 3rd ed; 2009.

196. Available from: http://nccam.nih.gov/health/reiki/introduction.htm. Accessed March 22, 2013.

197. Bowden D, Goddard L, Gruzelier J. A randomised controlled singleblind trial of the efficacy of Reiki at benefiting mood and well-being. Evid Based Complement Alternat Med. 2011;2011:381862.

198. Blumenthal JA, Babyak MA, Moore KA, et al. Effects of exercise training on older patients with major depression. Arch Intern Med. 1999;159:2349-2356.

199. Craft L, Landers D. The effect of exercise on clinical depression and depression resulting from medical illness. A meta-analysis. J Sport Exerc Psychol. 1998;20:339-357.

200. Otto MW, Church TS, Craft LL, Greer TL, Smits JA, Trivedi MH. Exercise for mood and anxiety disorders. J Clin Psychiatry. 2007;68: 669-676.

201. Dunn AL, Trivedi MH, Kampert JB, Clark CG, Chambliss HO. Exercise treatment for depression: efficacy and dose response. Am J Prev Med. 2005;28:1-8.

202. Richardson CR, Avripas SA, Neal DL, Marcus SM. Increasing lifestyle physical activity in patients with depression or other serious mental illness. J Psychiatr Pract. 2005;11:379-388.

203. Koch S, Morlinghaus K, Fuchs T. The joy dance: specific effects of a single dance intervention on psychiatric patients with depression. Arts Psychother. 2007;34:340-349.
204. [No authors listed]. Available from: https://thequantumalliance.zendesk.com/entries/21055146-indigo-contraindications-for-biofeedback. Accessed April 8, 2013.

205. [No authors listed]. Available from: http://www.electrostimulateursmanuels.fr/fichiers/publications/Contraindications-et-Precautions/ contraindications.pdf. Accessed April 8, 2013.

206. Karavidas M, Lehrer P, Vaschillo E, et al. Preliminary results of an open label study of heart rate variability biofeedback for the treatment of major depression. Appl Psychophysiol Biofeedback. 2007; 32(1):19-30.

207. Kim YHJ. The effectiveness of acupuncture for treating depression: a review. Alternative and Complementary Therapies. 2007.

208. Yeung AS, Ameral VE, Chuzi SE, Fava M, Mischoulon D. A pilot study of acupuncture augmentation therapy in antidepressant partial and non-responders with major depressive disorder. J Affect Disord. 2011;130:285-289.

209. Monti DA, Beitman BD, editors. Integrative Psychiatry. Oxford, UK: Oxford University Press; 2010.

210. Muskin PR, editor. Complementary and Alternative Medicine and Psychiatry. Arlington, VA: American Psychiatric Press Inc; 2000.

211. Mischoulan D, Rosenbaum JF. Natural Medications for Psychiatric Disorders, 2nd ed. Philadelphia, PA: Lippincott Williams \& Wilkins; 2008.

212. Ventegodt S, Merrick J. A review of side effects and adverse events of non-drug medicine (nonpharmaceutical complementary and alternative medicine): psychotherapy, mind-body medicine and clinical holistic medicine. J Complement Integr Med. 2009;6:16.

213. Mintz DL. Integrative approaches to depression and its treatment. Psychiatr Clin North Am. 2012;35:xiii-xvi.

214. Meyer B, Berger T, Caspar F, Beevers CG, Andersson G, Weiss M. Effectiveness of a novel integrative online treatment for depression (Deprexis): randomized controlled trial. J Med Internet Res. 2009;11:e15.

215. van Straten A, Cuijpers P, Smits N. Effectiveness of a web-based self-help intervention for symptoms of depression, anxiety, and stress: randomized controlled trial. J Med Internet Res. 2008;25: 10:e7.

216. Warmerdam L, van Straten A, Twisk J, Riper H, Cuijpers P. Internet-based treatment for adults with depressive symptoms: randomized controlled trial. J Med Internet Res. 2008;10:e44.

217. Clarke G, Eubanks D, Reid E, et al. Overcoming Depression on the Internet (ODIN) (2): a randomized trial of a self-help depression skills program with reminders. $J$ Med Internet Res. 2005; 7:e16.

218. Hoek W, Schuurmans J, Koot HM, Cuijpers P. Prevention of depression and anxiety in adolescents: a randomized controlled trial testing the efficacy and mechanisms of Internet-based self-help problem-solving therapy. Trials. 2009;10:93.
Neuropsychiatric Disease and Treatment

\section{Publish your work in this journal}

Neuropsychiatric Disease and Treatment is an international, peerreviewed journal of clinical therapeutics and pharmacology focusing on concise rapid reporting of clinical or pre-clinical studies on a range of neuropsychiatric and neurological disorders. This journal is indexed on PubMed Central, the 'PsycINFO' database and CAS.
Dovepress

The manuscript management system is completely online and includes a very quick and fair peer-review system, which is all easy to use. Visit http://www.dovepress.com/testimonials.php to read real quotes from published authors. 